\title{
EL PARQUE AGRÍCOLA: PARADIGMA PARA LA SALVAGUARDIA Y VALORIZACIÓN DEL PATRIMONIO RURAL. EL CASO DEL ÁREA SUR DE MILÁN (ITALIA) \\ Carlos Humberto Gómez Arciniegas*
}

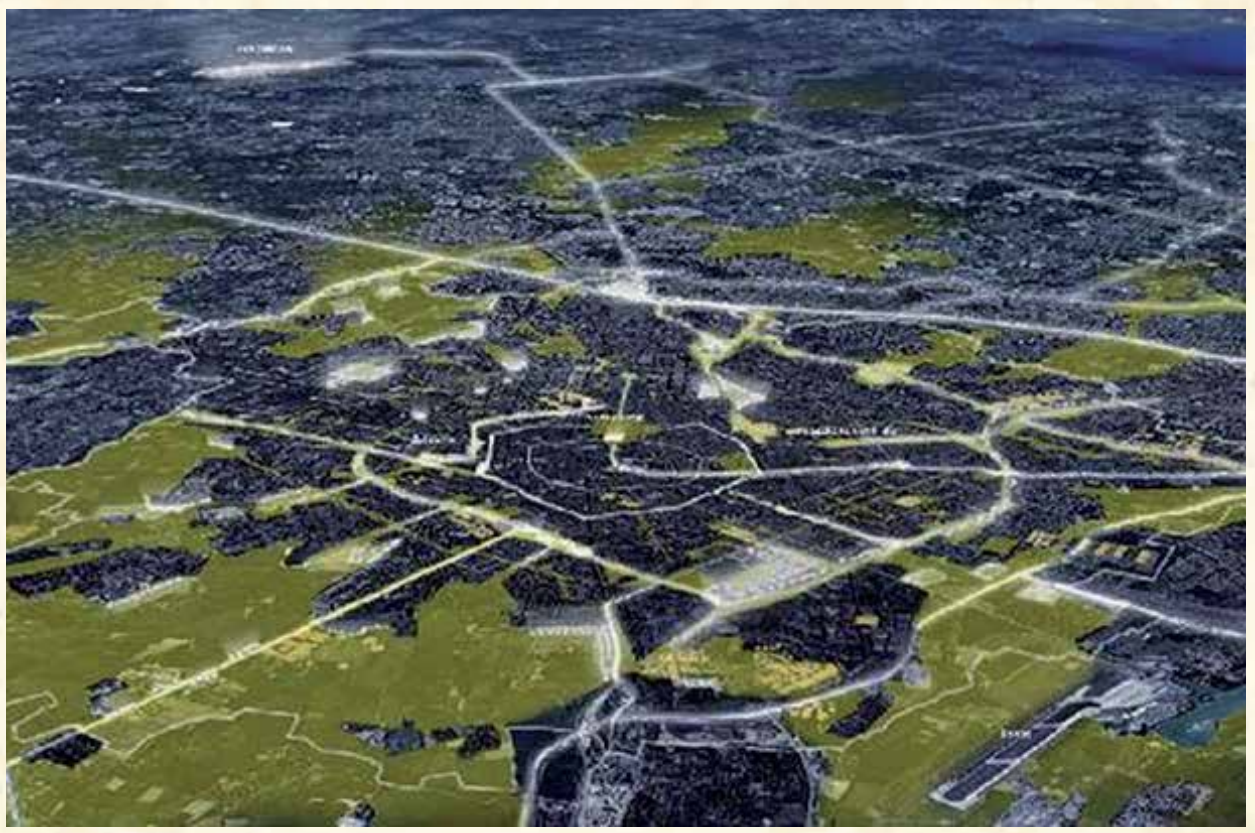

\section{RESUMEN}

El territorio rural, en sus diversas acepciones, reclama con urgencia una posición destacada como tema central de las disciplinas territoriales, no sólo en términos relacionados con la calidad del medio ambiente o del nivel de vida sino también en concordancia con la definición de planes y políticas de desarrollo auto sostenible, concebidos en beneficio del sector primario. Por lo tanto, la integración de la dimensión económica (agroalimentaria) con la ambiental (ecosistemas) y la cultural (histórica, paisajística y social) revela una nueva interpretación de la dinámica de los espacios rurales y prefigura, en concreto, nuevos instrumentos de ordenamiento del territorio como lo es el "Parque Agrícola". Este artículo analiza los aspectos más relevantes de esta tipología a través del estudio de un caso piloto, primer paradigma concebido en Lombardía (Italia), con el fin de comprender sus características, los instrumentos de planificación aplicados para su construcción y los mecanismos que se consolidaron para el gobierno de este territorio. Una exploración que apunta, además, a promover la utilización del modelo de "parque agrícola" como mecanismo para tutelar y potencializar el sector rural, resultante de la identificación de las múltiples dimensiones contextuales que lo caracterizan y que definen el carácter polifacético del patrimonio que allí reside.

\section{PALABRAS CLAVE}

Agricultura, áreas protegidas, gobernabilidad, gobierno, parque agrícola, patrimonio, territorio rural 


\section{THE AGRICULTURAL PARK: PARADIGM FOR THE PROTECTION AND EN HANCEMET OF RURAL HERITAGE}

Carlos Humberto Gómez Arciniegas*
Arquitecto Universidad Santo Tomás Bucaramanga - MSc. Lancaster University - Lancaster (Inglaterra) - PhD - Politecnico di Milano - Italia

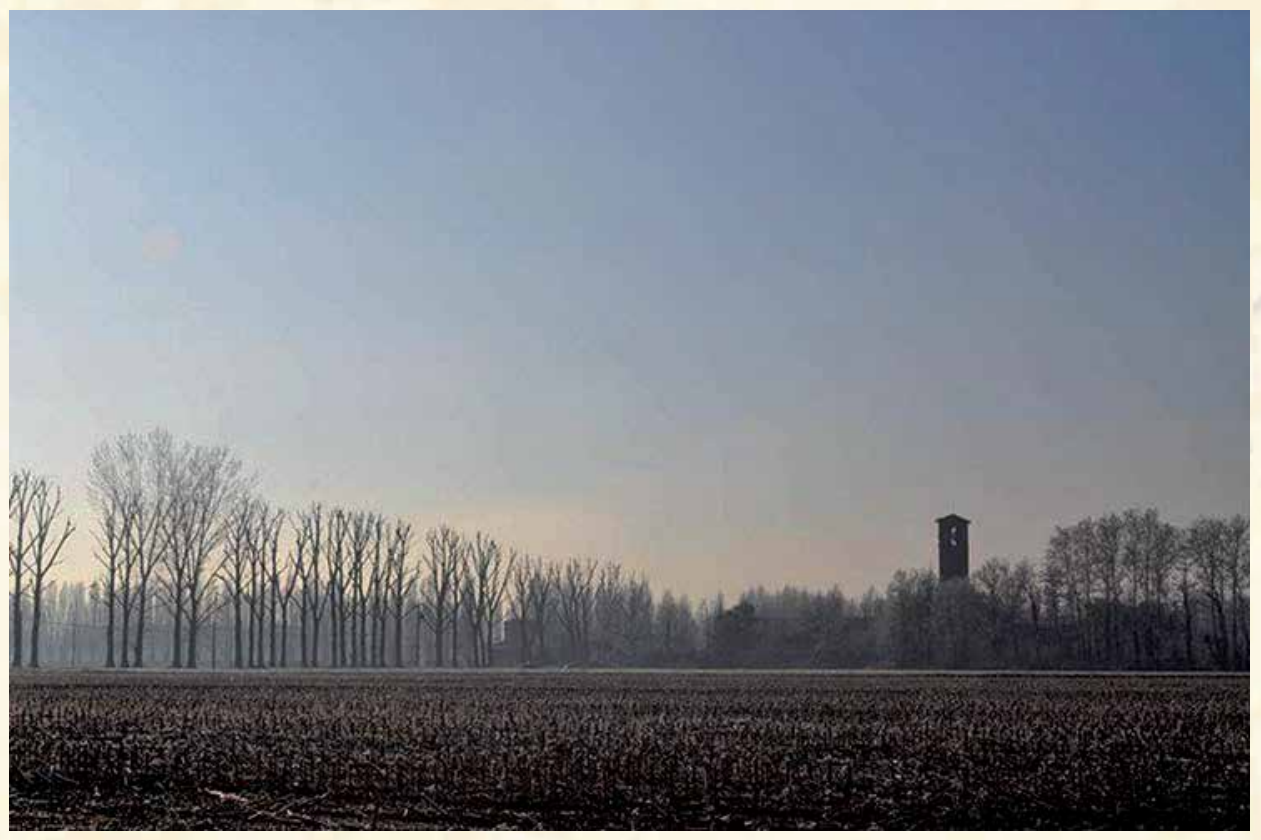

Fuente: Archivo del autor

\begin{abstract}
Rural areas within its various meanings, continues to demand urgently a core position as issue to be addressed by territorial disciplines, not only in terms related to environmental quality or standard of living but also in accordance with the definition of self-sustainable development plans and policies, conceived to enhance the primary sector. Therefore, the integration of dimensions such as economic (food supply), environmental (ecosystems) and cultural (historical, landscape and social) reveals a new interpretation of the dynamics of rural areas and anticipates, in particular, new tools for land use planning such as the "Agricultural Park". This article analyzes the most important aspects of this typology through a primary study case, first paradigm conceived in Lombardy (Italy), in order to understand its characteristics, planning tools applied to build it as well as the emerging mechanisms for the government of this territory. Thus, this exploration aims to promote the use of the concept of "agricultural park" as a mechanism to protect and empower the rural sector, by identifying the multiple dimensions that characterize and define the multifaceted character of the rural heritage.
\end{abstract}

\section{KEY WORDS}

Agriculture, protected areas, governance, government, agricultural park, heritage, rural area 


\section{INTRODUCCIÓN}

La nueva y creciente dimensión cualitativa y multi-referencial que se ha originado al extender la consideración patrimonial al territorio, ha llevado en los últimos años a decretar que éste, con todos sus recursos naturales, humanos, paisajísticos, culturales y económicos, constituya un bien común. Sin embargo, este nuevo calificativo del término "territorio" no excluye que éste haya sido objeto de estudio en múltiples disciplinas, que con propias construcciones de pensamiento lo han definido con múltiples acepciones desde hace siglos. De hecho, los romanos ya lo concebían como un gran "envolvente" que alojaba una red de ciudades (civitas)' que se intercalaban entre el ager y el saltus que conforman el paisaje rural. ${ }^{2}$ Hoy en día, el valor de las áreas rurales reclama con más fuerza la mirada de planificadores ante las evidentes amenazas y golpes dados por el proceso de expansión urbana, el cual genera detrimento y abandono de los espacios abiertos y evidencia, cada vez más, la inconsistencia de algunos modelos de planificación territorial que aventajan la dimensión urbana y subyugan la rural. Por el contrario, el espacio rural debe ser asumido como un "capital territorial" que amerita ser ordenado mediante oportunas estrategias y mecanismos, materializados a través de acciones que potencialicen su carácter y tipología. ${ }^{3}$ Aparece entonces la figura del "Parque Agrícola" como mecanismo dirigido a gestionar, proteger y valorizar el territorio que lo aloja y al mismo tiempo a ayudar a los actores económicos, sociales y culturales allí presentes, participes creativos en la formación de proyectos pensados para aumentar el valor del patrimonio local. En síntesis, el presente artículo hace un recorrido que va desde la definición del territorio rural como patrimonio merecedor de una adecuada gestión, para sucesivamente aproximarse a las estrategias más importantes que se han originado en el norte de Italia en favor del patrimonio rural, hasta desembocar en la aparición de los parques regionales, entre estos últimos el Parque Agrícola del Sur de Milán (PASM).

Este parque, primer paradigma europeo, ostenta un territorio con un gran acervo patrimonial en el que una enorme cantidad de componentes se ordenan gracias a las sinergias creadas entre los habitantes de los 61 municipios asociados al Parque y los actores políticos involucrados, en el marco de un significativo proceso de planificación y gobierno del territorio. Esto es esencia el contenido del presente trabajo, el cual propende por describir los desafíos y los logros, asumidos por el PASM, receptáculo de una diversidad de componentes que merecen ser escrutados y puestos sobre la mesa para futuras reflexiones que lleven a considerar el territorio rural en nuestro país como magnánimo patrimonio que merece nuevas estrategias y mecanismos para protegerlo.

\section{EL TERRITORIO RURAL COMO PATRIMONIO}

El carácter universal que ha asumido el territorio rural lleva a apreciarlo por su condición interdisciplinar puesto que en sus variados y dispares términos, yace una riqueza patrimonial lista para ser fecundada y racionalmente utilizada. En este sentido, el paisaje rural se conforma como

I Sexto Pomponio, jurista romano, circunscribía las áreas rurales en su definición de territorîum: Universitas agorum intra fines cuiusque civitatis" o sea "la totalidad de los campos entre los límites de cualquier ciudad" y de los cuales dependía en gran parte la sostenibilidad del imperio romano. CELLURALE, María Teresa. Locus e lus. Observaciones sobre espacio y sistema a la luz del derecho romano, Revista de Derecho Privado, Universidad Externado de Colombia, ISSN 0I23-4366, No. 16, 2009, pp. 40-4I

2 BUZO SÁNCHEZ, Isaac. Apuntes de Geografía Humana, IES Extremadura, Montijo, 2009

3 ACEVES GONZÁLEZ, Francisco de Jesús. La territorialidad: punto nodal en la intersección espacio urbano-procesos en Comunicación y Sociedad, No. 30, DESC, Universidad de Guadalajara, Guadalajara mayo-agosto, 1997. pp. 275-30I 
"el resultado de la acción de la sociedad sobre dicho medio durante la historia, y por lo tanto, un excelente escaparate del patrimonio rural, que necesariamente precisa de una interpretación por parte de los investigadores". ${ }^{4}$

No lejana a esta conceptualización está uno de los tres enfoques al desarrollo local sostenible de Alberto Magnaghi, preocupado por las relaciones entre ambiente construido, ambiente natural y ambiente antrópico (enfoque territorialista). ${ }^{5}$ Entran aquí en juego los propósitos de la planificación territorial que se enfocan hacia la reducción de los desequilibrios entre los espacios abiertos y los construidos, así como en pos de la gestión de las relaciones entre ciudad y el agro, entre otros. ${ }^{6}$ Así bien, es posible concluir, basándose en la apreciación hecha por De Matteis, que el territorio rural no es una simpleza geográfica $\circ$ una mera entidad material sino un conjunto bien complejo de relaciones que merecen ser sopesadas, valoradas y protegidas como un patrimonio indivisible que será heredado de generación en generación. ${ }^{7}$ Por lo tanto, las poblaciones del planeta, deseosas de tomar la vanguardia en términos de sostenibilidad, tienen que adoptar una amplia definición de patrimonio que identifique $y$ asocie el territorio rural a lugares y a personas, a su carácter y a sus valores ambientales, paisajísticos y urbanos, así como a su legado cultural, todo en el ámbito de una marco de una plena singularidad reconocible entre el pasado y el futuro. Ante estas premisas, sobresale el territorio rural de la Unión Europea y sus múltiples actores, entre estos el pueblo italiano, el cual lo ha sabido proteger y valorizar, considerándolo como una heredad gracias a la conciencia social sobre el inmenso patrimonio natural y cultural que este espacio atesora y que hoy sirve de garante para el desarrollo sostenible del país. ${ }^{8}$

\section{DESDE LAS ÁREAS PROTEGIDAS HASTA EL PARQUE AGRÍCO- LA: UN NUEVO MECANISMO PARA LA SALVAGUARDIA DEL PATRIMONIO RURAL}

Hablar hoy de proteger un territorio, significa ir más allá del concepto de "naturaleza salvaje e inaccesible" e incluso de la idea de "santuario", donde simplemente se reservan especies de animales y plantas para contemplarlos en su hábitat natural. Se debe recurrir por tanto al concepto del área protegida, entendida a través de la multiplicidad de sus formas como un "espacio privilegiado" pero apto además para promover el desarrollo económico y social de las comunidades locales y experimentar nuevas formas de relación con la naturaleza, traducidas en actividades educativas, recreativas y deportivas respetuosas de los delicados equilibrios ambientales. Es así que en el territorio italiano, las áreas naturales protegidas representan un escenario considerable que custodia una parte muy importante del patrimonio natural, paisajístico y cultural de la nación. Cabe destacar que la Región Lombardía fue la primera en Italia en adoptar un sistema orgánico de áreas protegidas ya que en 1973, con la Ley Regional No. 58, se dictaron las primeras normas para la institución de parques y reservas naturales y sobre las bases de esta ley fueron creados los primeros parques regionales. ${ }^{9}$

\footnotetext{
HERMOSILLA PLA, Jorge. ¿Conocer el patrimonio rural Lujo o necesidad? En el Lebrillo Cultural. No, 2I, Venta del Moro, 2004

5 MAGNAGHI, Alberto. II Progetto Locale. Torino, Ed. Ballati Bonghieri, 2000

6 TURCO, Angelo. Versouna Teoria Geografica della Complessità. Studi e Ricerche Sul Territorio. Milano, Ed. Unocopli, 1988

7 DEMATTEIS, Giuseppe. Le metafore della terra. La geografia umana tra mito e scienza. Milano, Feltrinelli, 1985

8 Los inmensos atributos del territorio rural de la Unión Europea contribuyen a ubicar muchos de sus Estados miembros en las primeras posiciones mundiales de los países que perciben más ingresos derivados del turismo internacional, entre estos se destacan Francia, Italia y España. United Nations World Turism Organisation, www.unwto.org

9 Se hace referencia a los siguientes parques: Ticino, Groane y Colli de Bérgamo. Agenzia Regionale per la Protezione dell'Ambiente. ARPA LOMBARDIA, Aree Protette della Lombardia in Revista Segnali Ambientali, ARPA, Milano, 2002, pp. $129-130$
} 
Mapa I. El Sistema Verde de la Provincia de Milán

Fuente: El Sistema Verde de la Provincia de Milán envuelve todas las categorías de las áreas protegidas. Parques Locales de Interés Supramunicipal (PLIS) reconocidos y propuestos, reservas naturales, parques regionales, entre estos el Parque Agrícola Sud Milano. Cartografía disponible en Internet en http://www.provincia milano.it/export/sites/default/pianificazione_ territoriale/img/provincia_plis_2006_p.gif
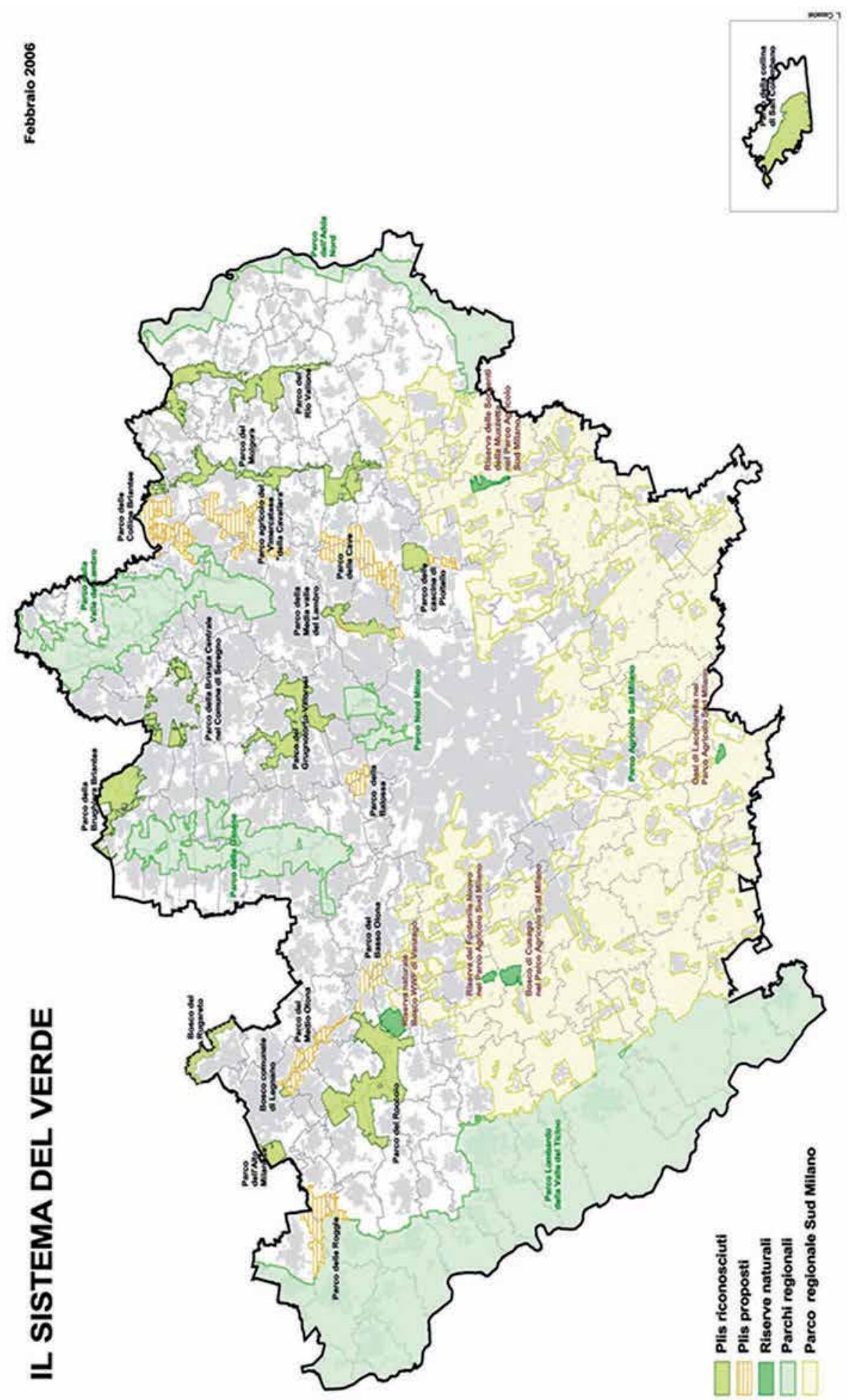
La salvaguarda del territorio rural Lombardo se consolida definitivamente gracias a la Ley regional No. 86 de 1983 por la cual se estableció el "Sistema de Áreas Protegidas Lombardía". ${ }^{10}$ Mediante este instrumento de planificación se ordena un inmenso patrimonio territorial denominado "Sistema del Verde" de la Provincia de Milán (Ver Mapa I), una red formada por sus 5 Parques Regionales, entre ellos el Parque Agrícola Sur de Milán, 16 Parques locales de interés supramunicipal (PLIS), I Reserva Natural fuera de los parques (Vanzago), 6 sitios de importancia comunitaria para efectos de la Directriz "Hábitats" y I zona de protección especial (el Ticino) para la Directriz "Aves" (Ver Fig. I)."

Ahondando en el ámbito de la planificación, el establecimiento de estas áreas protegidas implica la creación de estrategias que van más allá de la tutela del territorio y que incluyen además mecanismos específicos para la promoción turística y el desarrollo sostenible, situación que es notoria en el contexto agro-silvo-pastoril ya que estos objetivos se realizan integrando las actividades humanas con la protección del medio ambiente. En otras palabras, se considera el entorno en el que se inserta el área protegida tratando de integrar el medio ambiente natural con el antropizado. Se trata de diferentes territorios rurales, sobresalientes no sólo por el medio ambiente natural y los testimonios histórico-culturales allí presentes sino también por otros factores como su organización, las responsabilidades de gestión, los vínculos legales y los niveles de protección; en fin, áreas especiales que constituyen una especie de laboratorios en los cuales experimentar nuevas formas de desarrollo sostenible.

Entran aquí en escena los Parques Agrícolas que pueden ser considerados como conectores, con caracteres diferentes, en las redes de uso social del territorio prefiguradas para el ocio, el esparcimiento, la contemplación y descubrimiento de la naturaleza, la recreación al área libre, la educación ambiental e inclusive para la "inspiración espiritual" 2 y, al mismo tiempo, como "proyectos territoriales ejemplares donde se reconstituye la relación evolutiva y conjunta entre el medio ambiente, la vivienda, la producción y el consumo, inclusive de bienes públicos y activos intangibles". ${ }^{13}$

Citar ejemplos podría ser bastante ambicioso ya que después del nacimiento del primer paradigma en Milán (Italia) los Parques Agrícolas han hecho su aparición con una misión común destinada a mantener los valores tradicionales del medio ambiente y del paisaje de las zonas rurales así como a la salvaguardia y cualificación de los sistemas agro-silvo-pastorales, estrechamente ligada a la prevención de los efectos nocivos de origen humano y la fruición del suelo para uso educativo, cultural, científico y recreativo. Es así que desde la región metropolitana de Lisboa, pasando por el Parque Agrario del Baix Llobregat en Barcelona (España), hasta los territorios rurales de Alemania y Holanda se advierten proyectos de parques agrícolas que apuntan a dar una respuesta a procesos bastantes complejos de transformación debidos a la segregación del uso residencial, las diferencias sociales, los procesos de privatización y la fragmentación de los espacios abiertos, todo esto fruto de la expansión urbana sobre el campo. ${ }^{14}$ Los resultados son el fruto de un proceso en el cual cada municipio ha desarrollado un enfoque claramente orientado, haciendo uso referencial de varios contextos locales, para sondear y verificar la coherencia del paradigma disciplinario del "parque agrícola", tratando de confrontar un específico número de aspec-

10 El primer parque regional creado en Italia es el Parco Lombardo del Ticino. Nace en 1974 para defender el río Ticino y los ecosistemas naturales del Valle del Ticino de los ataques de la industrialización y de una urbanización, cada día más invasiva. http://www.parcoticino.it

II http://www.provincia.milano.it/pianificazione_territoriale/parchi/La_rete_dei_Parchi.html

12 GAMBINO, R. Progetti per l'ambiente. Milano, F. Angeli, 1997

13 PERNA, T. Aspromonte: i parchi nazionali nello sviluppo locale. Torino, Bollati Boringhieri, 2002

14 La Provincia de Milán sugiere un estudio profundo de otros casos dados en algunas ciudades europeas como París, Londres, Randstad y Frankfurt. Al respecto consúltese http://www.provincia.milano.it/parcosud/natura/index.html 
Figura I. Ubicación del Parque Agrícola Sur de Milán dentro de las principales áreas protegidas de la Provincia di Milano

Fuente: En este territorio es actualmente reconocida una totalidad de 16 PLIS (de los cuales 9 interprovinciales), que interesan una totalidad de 40 municipios y una superficie aproximada de 6.986 ha. Otros 5 PLIS, en otra época de la Provincia de Milán, hacen ahora parte del ámbito territorial de la nueva Provincia de Monza y Brianza. El gráfico fue elaborado por el autor con base en la información recopilada en http://www.provincia.milano.it/pianificazione territoriale/parchi/La_rete_dei_Parchi.html y www.parks.it

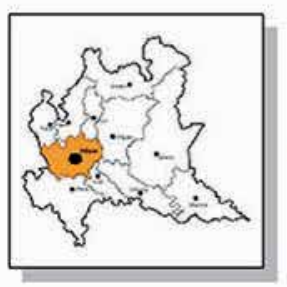

\section{Principales áreas protegidas de la Provincia de Milán}
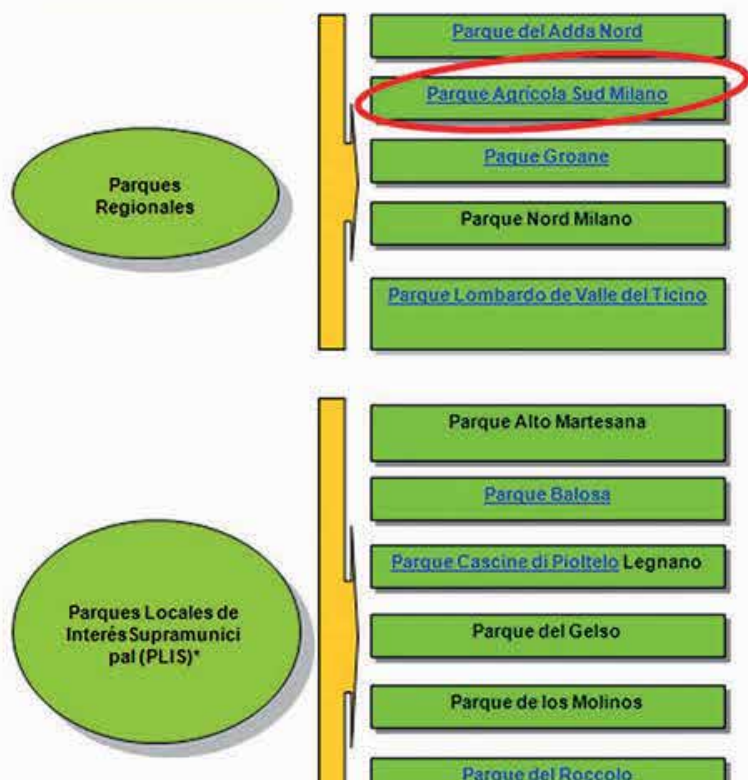

Pargue Cascine di Pioltelo Legnano
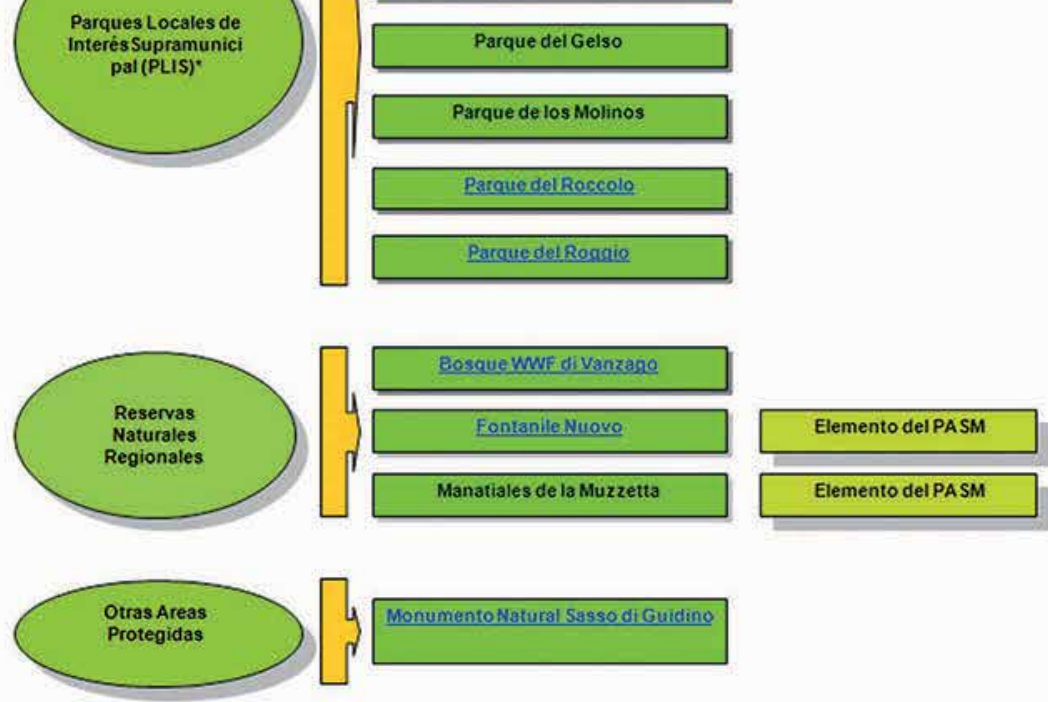

Monumento Natural Sasso di Guidino 
tos, previamente identificados por investigadores y estudiosos de los Parques Agrícolas. Específicamente se trata de hacer una cuidadosa lectura del territorio que alojará el nuevo parque para alcanzar los siguientes objetivos puntuales: ${ }^{15}$

- Conservar y reforzar las actividades agrícolas, incluida la comercialización de los productos locales y la apropiación de cultivos de alta compatibilidad ambiental de acuerdo con el "Código de Buenas prácticas Agrícolas" (artículo 1999/I 257/CE) como la agricultura orgánica y la agricultura biodinámica.

- Proteger y valorizar el patrimonio natural, ambiental y paisajístico.

- Preservar, restaurar y restablecer la retícula fluvial.

- Recuperar y reutilizar los tejidos territoriales y los edificios existentes, dando especial atención a los abandonados.

- Recuperar y valorizar los bienes del patrimonio arqueológico y monumental.

- Establecimiento de un sistema de fruición pública mediante la adquisición de terrenos de uso público, la construcción de itinerarios naturalísticos con rutas para peatones y ciclistas y la introducción o mejora de usos recreativos, receptivos, deportivos y de servicio

Una vez asumidos los objetivos más pertinentes al contexto se hace necesario redefinir esquemas que contemplen las siguientes estrategias territoriales: ${ }^{16}$

- Estructurar asentamientos policéntricos y sostenibles basados en la complementariedad entre las ciudades y zonas rurales.

- Propender por la producción integrada de bienes públicos (ambientales), sociales y culturales $y$, en modo más general, del entorno construido en contextos con elevada expansión urbana.

- Definir patrones para la gestión y la promoción de una cultura de los espacios abiertos y de los parques, diseñados a favor de una interacción evolutiva entre la sociedad asentada, la producción agrícola y la calidad del paisaje.

- Formar y apoyar las redes de actores locales para apoyar nuevos modos de producción y consumo basado en relaciones beneficiarias y, por ende, redes de comercialización vecinas y sensibles a la calidad y la caracterización local del producto.

- Establecer modelos de desarrollo local, de planificación integrada y multisectorial capaces de integrar la dimensión territorial y económica del desarrollo.

Para llegar a las anteriores finalidades las unidades de investigación desarrollan el programa en relación a los diferentes contextos locales valiéndose de los siguientes procesos: ${ }^{17}$

- Construcción de los marcos cognoscitivos, en los diversos contextos, sobre los resultados de la experimentación en curso de las indicaciones inmediatamente anteriores, esperando resultados como nuevas producciones, redes de cooperación, direccionamiento de proyectos y en el mejor de los casos la formación de los parques agrícolas.

- Nuevos instrumentos de planificación estratégica (a escala municipal y supramunicipales) para activar procesos de integración de políticas, acciones y proyectos en los

15 Sistema Informativo territorial integrado. Alcaldía de Roma. Parques Agrícolas [Objetivos]. Información disponible en Internet en http://www.h50I .net/art72-prg-roma-parchi-agricoli.aspx

16 Ricerca Italiana, The Agricultural Park: a New Territorial Planning Instrument for Un built Areas, Università degli Studi di Firenze, http://www.ricercaitaliana.it/

17 lbídem 
escenarios de la producción agrícola, así como en el contexto ambiental, paisajístico, económico y de fruición.

- Estudios de escenarios territoriales, potencialmente relacionables con la tipología del parques agrícola y llevados a cabo en las zonas periurbanas y metropolitanas y en la rehabilitación de los sistemas fluviales, costeros y montañosos.

- Identificación de conocimientos técnicos con el fin de activar experiencias de nueva producción, de formación de parques y proyectos agrícolas y de redes de aprovechamiento de los productos $y$ de las condiciones $y$ herramientas operativas. ${ }^{18}$

Es importante anotar que todo este marco organizativo, enfocado hacia la implementación y sostenibilidad de los Parques Agrícolas, aporta encuadramientos generales y no está dirigido a ningún contexto específico. Es tarea de los planificadores entender y predecir, en todas sus dimensiones, las afectaciones que pueda sufrir el territorio rural a causa de las dinámicas que se darán ante la estructuración de un parque agrícola. Sin embargo, el paradigma italiano aporta válidos argumentos propositivos, apoyados en nuevos instrumentos de planificación y mecanismos de gestión que han servido para afrontar la falta de orden y coordinación, característicos de los años sesenta y setenta, la cual dejó profundas cicatrices en el paisaje rural y periurbano de muchas regiones italianas: campos cultivados en convivencia con almacenes y supermercados, implantados a lo largo de carreteras principales y viaductos, fábricas abandonadas, tierras inutilizadas y localidades carentes de equipamientos básicos. ${ }^{19}$

En síntesis, el parque agrícola puede propiciar un nuevo territorio mediante una relación fértil entre el elemento humano y el medio ambiente, un "desarrollo local sostenible" basado en la interacción de tres elementos esenciales (naturaleza, historia y cultura) con las condiciones de cada zona. ${ }^{20}$ Se hace entonces necesario un análisis más detallado de una tipología, en este caso el Parque Agrícola Sur de Milán, antes de establecer condiciones sobre la viabilidad de los parques agrícolas como mecanismo de planificación en el contexto colombiano.

\section{LOS INSTRUMENTOS DE PLANIFICACIÓN DEL PARQUE AGRÍ- COLA SUR DE MILÁN (PASM)}

Como se mencionó anteriormente, los Parques Agrícolas italianos se encuentran, junto a los Parques Fluviales, Parques forestales y de Cinturón Metropolitano, dentro de la categoría de los Parques Regionales, establecidos a lo largo de los años con leyes regionales específicas para ser finalmente ordenados en el marco del Plan General de Áreas Protegidas. ${ }^{21}$ Sin embargo, los instrumentos de planificación que fueron la génesis del PASM se remontan a tres años antes del Plan General y están contenidos en el Plan Regulador General (PRG) del municipio de Milán, emanado en 1980 y equivalente a un plan de ordenamiento territorial. ${ }^{22}$ Aunque años después se efectuaron algunas modificaciones estratégicas debidos a problemas surgidos en su implantación, el Plan contaba con disposiciones que se ocupaban del "verde agrícola" y por ende velaba por regular la expansión

18 Ibidem

19 CAPOZZI, B.; PERABONI, C.; TREU, M. C. I nuovi segni del territorio, 2004

20 LAPEI. Laboratorio di Progettazione Ecologica degli Insediamenti. Forum Sociale Mondiale. Carta del Nuovo Municipio, 2002. www.unifi.it/lapei

21 Las áreas protegidas identificadas en el Plan están sujetas a un régimen de tutela según su denominación: parques naturales, parques regionales, reservas naturales, monumentos naturales y zonas de importancia natural. Región Lombardía, Ley Regional del 30 de noviembre de 1983. Plan Regional de las Áreas Protegidas, Normas para la instauración y gestión de las reservas, los parques y los monumentos naturales como también de las áreas de particular relevancia natural y ambiental, Región Lombardía, Milán, 1983. http://www.provincia.milano.it/ pianificazione_territoriale/parchi/parchi_regionali/index.html

22 Comune di Milano, Normas Técnicas de Aplicación del Plan Regulador General (PRG), aprobado el 26/2/1980, con las modificaciones aportadas al variante aprobado por la Junta Regional Lombarda el 5/7/1988 deliberación n. 35625, Milán, 1988 
de la ciudad hacia la periferia. ${ }^{23}$ Es así, que el Plan dimensionaba nuevas áreas destinadas a zonas residenciales con capacidades máximas de habitabilidad dependiendo del tipo de zona $y$, al mismo tiempo, incentivar intervenciones de recuperación urbanística en áreas internas de la ciudad de Milán, afectadas o amenazadas por fenómenos de degradación y subutilizadas. Sin embargo, la falta de un nivel de gobierno superior con potestades de control y supervisión hacia el Municipio de Milán, característica de los años ochenta, sumado a la aplicación discordante y sin continuidad de las estrategias del Plan, dejó serios desequilibrios en la organización del territorio. ${ }^{24}$

Esta problemática de gestión que afrontaba el municipio de Milán y otros cien municipios del hinterland (esfera de influencia del municipio de Milán) ve una nueva luz en 1990 después de que el Estado italiano entregó competencias en materia de planificación a las Provincias (componentes de cada Región italiana) mediante la intitulada "Ley Nacional de Reforma y Ordenamiento Local No. 142/1990". Acto seguido la Provincia de Milán promueve el Plano Territorial de Coordinación Provincial (PTCP) para solucionar los problemas de desequilibrio y desestructuración territorial que afrontaba el área metropolitana de Milán así como dar respuesta a los desafíos de competitividad y a las exigencias por una mejor calidad de vida de los habitantes En otras palabras, un proyecto estratégico de desarrollo que proporciona indicaciones sobre posibles objetivos y estrategias a mediano y largo plazo, dirigidas al ordenamiento territorial desde una escala provincial hasta una escala local pero que no daba respuesta al tipo de equilibrio posible entre los dos desafíos existentes. La operación más innovadora derivada del PTCP fue la de la institución del Parque Regional de Cinturón Metropolitano denominado Parque Agrícola Sud Milano (PASM) mediante la aplicación de la Ley regional No. 24, del 23 de abril de $1990^{25}$ (Ver Mapa 2).

La mayor fortaleza del parque es su estructura organizativa, propia e innovadora, que fusiona el ámbito de la planificación y el desarrollo económico. Consta de un ente gestor, la Provincia de Milán, que administra el parque según el Plan Territorial de Coordinación del parque (PTC) ${ }^{26}$ y el Plan del Sector Agrícola (PSA). ${ }^{27}$ El objetivo primordial del PTC es la articulación del territorio en áreas de actividad para las distintas características de las actividades (trabajo, paisaje y presencia humana, entre otros) destinadas a un uso por su sistema de protección. Actúa con diferentes criterios para lo que se articula espacialmente en cinco áreas principales: territorios agrícolas, ámbitos de los resguardos paisajísticos y naturales, ámbito de la utilización, elementos puntuales de tutela ambiental, paisajística, arquitectónica y monumental y áreas de tratamiento especial..$^{28}$ Dentro de los poderes de PTC resalta el Título III, Art. 24, sobre intervenciones edilicias inherentes a la actividad agrícola y con la cual se regula toda actividad constructiva en el Parque. Paralelamente el ente gestor del Parque presenta estos elementos a la ciudadanía en 5 renglones que envuelven dichas áreas: municipios (léase los $6 \mathrm{I}$ asociados al parque), agricultura, monumentos, naturaleza y "puntos parque" o centros de encuentro e información ciudadana (ver Figura 2). ${ }^{29}$

23 Ibídem

24 MORATALLA ZAZO, Ana. El Parque Agrícola del Sur de Milán: La primera incorporación de un espacio agrícola periurbano al sistema urbano. El principio de una era de parques en el Espacio agrícola entre el campo y la ciudad, Universidad Politécnica de Madrid, Madrid, 2010

25 Información disponible en Internet en http://www.provincia.milano.it/parcosud/regolamento/legge.html

26 Región Lombardía. Aprobación del Plan Territorial de Coordinación del Parque Regional Agrícola Sur Milán (Art. I, 2, I.r. 86/83 y sucesivas modificaciones) por Deliberación del Gabinete Regional del 3 de agosto de 2000 en Boletín Oficial, 2 do. Suplemento extraordinario del numero 38, Milán, 2000

27 Provincia di Milano, Plan del Sector Agrícola, Aprobado por el Consejo Directivo del Parco Agricolo Sud Milano con deliberación número 33 del 17 de julio de 2007, observando las NTA del PTC, Milano, 2007, disponible en Internet en: http:// www.provincia.milano.it/parcosud/

28 Región Lombardía. Plan Territorial de Coordinación del Parque Regional Agrícola Sur de Milán, Op. cit.

29 Parco Agricolo Sud Milano disponible en Internet en: http://www.provincia.mi.it/parcosud/index.jsp 
Mapa 2. El rol multifacético del PASM

Fuente: Limitar la acción abrasiva de la constante expansión urbana, preservar la agricultura y servir además como pulmón verde para el área metropolitana de Milán. En su calidad de "parque agrícola" abarca una extensa área en forma de semicírculo a lo largo del perímetro sur de la Provincia de Milán, haciendo de este modo parte de lo que se prevé como el cinturón verde milanés. Cartografía disponible en Internet en http://provincia.milano.it

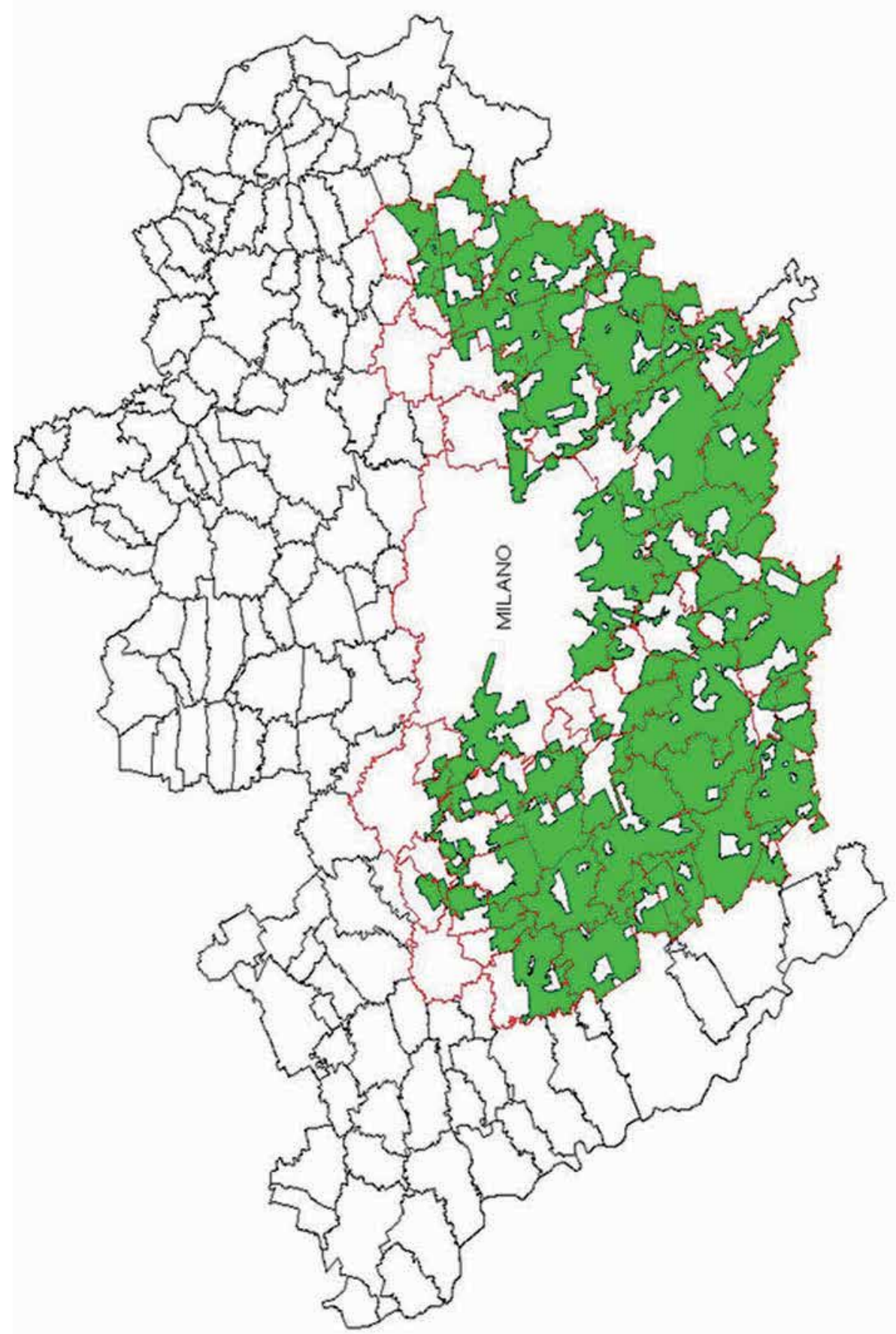




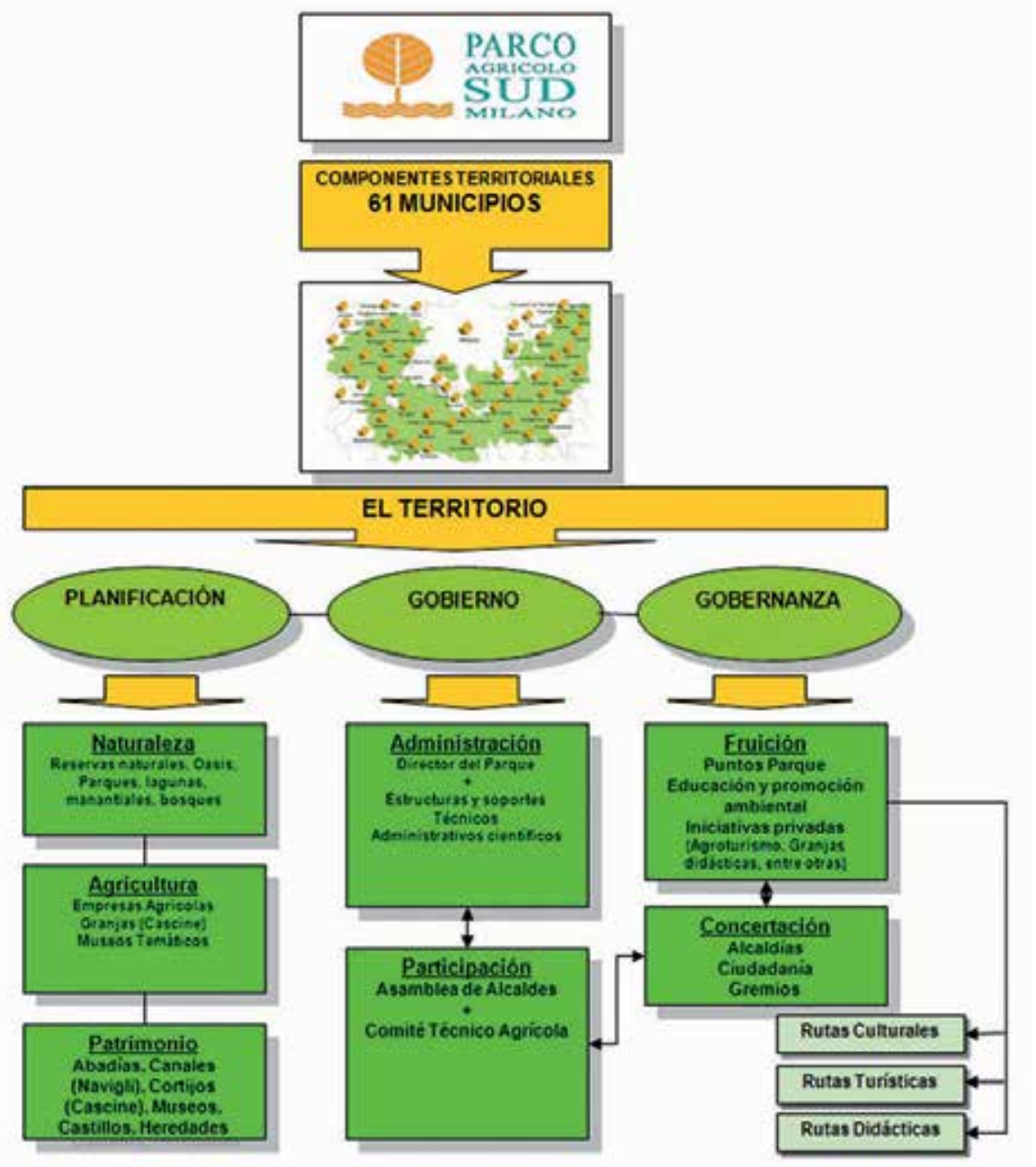

En cuanto al sector primario como tal, el instrumento regulador es el Plano del sector Agrícola (PSA) cuyo objetivo principal es coordinar y orientar técnicamente la producción agrícola bajo las disposiciones de la ley de creación del parque y el PTC. Asimismo, el PSA realizó un censo del Parque para elaborar una base de datos gestionada a través de un sistema de información geográfica (SIG). Se trata del Sistema Informativo Territorial para el Parque Agrícola Sur de Milán (SITPAS) cuyo objetivo es guiar a los agricultores en la rentabilidad y protección del medio ambiente mediante una gestión racional de los recursos, una adecuada planificación territorial y el consejo en la selección de cultivos y ganadería apropiada. ${ }^{30}$

Esta organización y clasificación de los componentes territoriales del PASM pone en claro como se opera para un adecuado ordenamiento y conservación de todos los elementos, trópicos y antrópicos, dentro del tejido relativamente denso que forman las unidades de producción agrícola, el cual requiere además de normas y al mismo tiempo incentivos. Haciendo nuevamente referencia a los elementos articuladores del territorio del parque, este trabajo trata de aproximarse brevemente a los componentes de cada uno de estos.

30 EI SITPAS contiene datos de los análisis sobre las características socio-económicas de las explotaciones en los siguientes aspectos: número de empresas que operan en el parque (unas 800 ), superficie, forma jurídica, tipo y tamaño de la fuerza de trabajo, propiedad del suelo, tipologías de complejos rurales y nivel de mecanización de las explotaciones, entre otros. Para mayor información consúltese http://www.provincia.mi.it/parcosud/sitpas/index.html
Figura 2. La planificación y gestión del territorio del Parque

Fuente: El área del PASM está conformado por el territorio no edificado (áreas libres), existente en los 6 I municipios asociados. Este territorio está ordenado mediante una oportuna planificación del patrimonio existente, protegido y valorizado mediante procesos transversales de gobierno $y$ gobernabilidad a múltiples escalas. La gráfica fue elaborada por el autor 


\section{EL ORDENAMIENTO DEL TERRITORIO DEL PARQUE}

Entre los parques regionales que existen en el territorio de la Provincia de Milán, el PASM es sin duda el proyecto más grande y complejo promovido por la Región Lombardía. De hecho el proyecto interesa aproximadamente un tercio del territorio de la provincia y 61 municipios. Esto no sólo por la dimensión del área del parque, que con sus 48.000 hectáreas de superficie terrestre lo ubican en una posición de liderazgo entre los parques agrícolas en Europa, sino también y sobre todo por los objetivos estratégicos que el PASM persigue:

- El equilibrio ecológico y la sostenibilidad de los futuros desarrollos del área metropolitana

- La conservación y clasificación de las tierras agrícolas productivas y el paisaje agrícola histórico

- La conexión del territorio agrícola externo con el sistema verde urbano

- El uso contemporáneo de este vasto territorio agrícola con fines de utilizarlo para la cultura, el ocio, el deporte y el tiempo libre del usuario local y metropolitano. ${ }^{31}$

El alcance de estos objetivos inicia con una planificación sectorial del territorio del parque, conyugada a una serie de mecanismos de gobierno que contempla el título III del PTC denominado "Articulación del Territorio del Parque", el cual se subdivide, a su vez, en cinco secciones. La primera de estas se sustenta con el ordenamiento de los suelos agrícolas bajo tres categorías (ver Mapa 3):

Mapa 3. Usos del suelo del PASM

Fuente: Resaltan, en amarillo, los territorios agrícolas y en gris las aéreas urbanizadas ubicadas en el cinturón metropolitano de la Provincia de Milán. La cartografía fue extraída del Plan del Sector Agrícola, Tabla 5. Puede ser

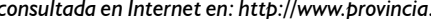
mi.it/parcosud/psa/index.html

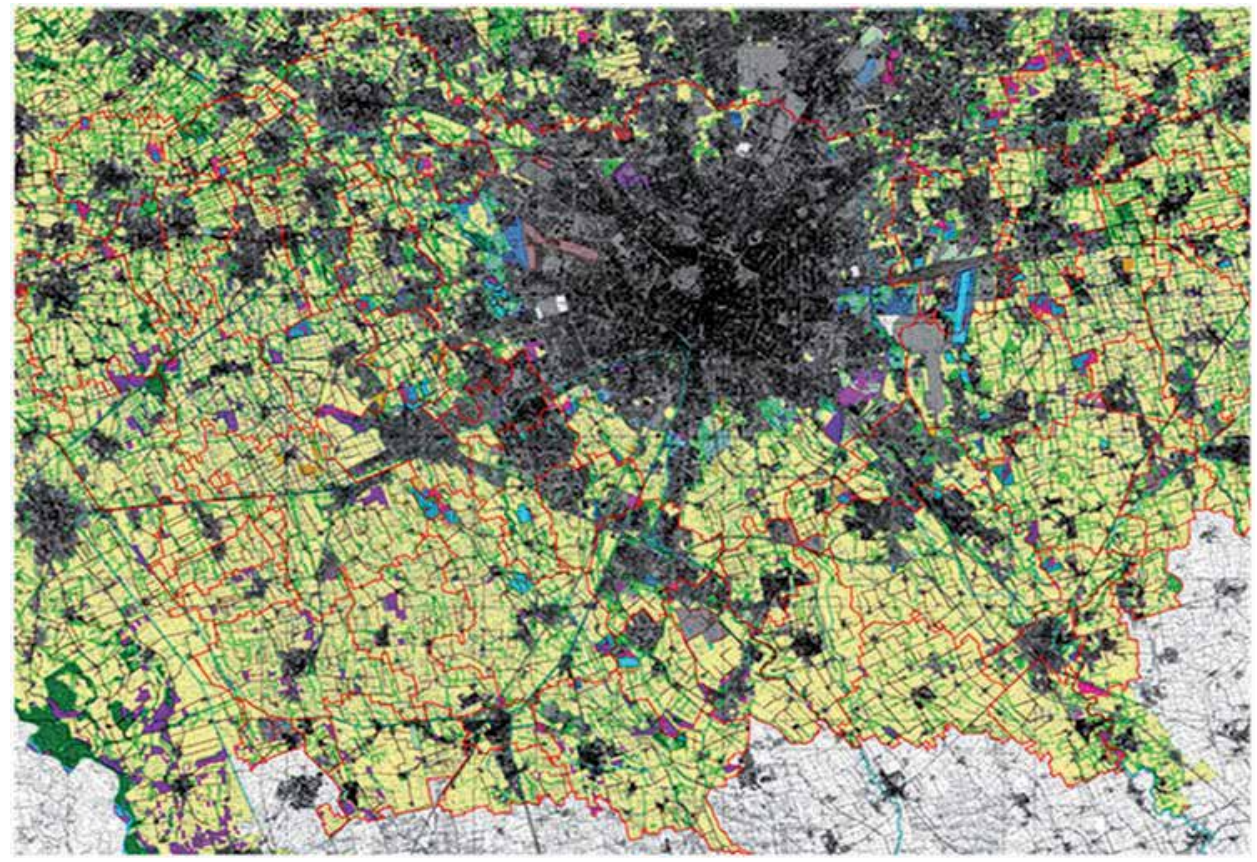

- Los territorios agrícolas del cinturón metropolitano, (el 85,5\% del parque). Incluyen los ámbitos localizados en las partes periféricas de la zona metropolitana que se mantienen más compactos e intactos. La actividad agrícola se desarrolla en todo su potencial productivo en suelo destinado a impedir la creación de nuevas infraestructuras y construcciones que lleven a la fragmentación del territorio. ${ }^{32}$

I Parco Agricolo Sud Milano. Generalità. Información disponible en Internet en: http://temi.provincia.milano. it/parcosud/titolol .htm

32 Centro di Studi per la Programmazione Intercomunale dell'Area Metropolitana. Plan territorial de Coordinación del Parque Agrícola Sur de Milán, disponible en Internet en: http://www.pim.mi.it/index.html 
- Los territorios agrícolas y verde del cinturón urbano, (el 10\% del parque). Incluidos dentro del anillo de circunvalación de Milán. Es la zona en contacto más directo con el núcleo urbano y, por lo tanto, la que sufre más agresiones al tejido rural agrícola. ${ }^{33}$

- Los territorios de conexión entre campo y ciudad, (5\% del parque). No gozan de gran importancia en términos agrícolas debido a su fragmentación y a su carácter es residual debido a la continua agresión de la urbanización. En estas zonas la función de PTC se centra en la creación y la mejora del contexto histórico para renovar las funciones ecológicas o las zonas agrícolas. ${ }^{34}$

Junto a la función de la agricultura como instrumento de planificación territorial sobresale además en cualquiera de las 3 categorías, anteriormente expuestas, su importante valor desde el punto de vista de su extraordinaria transformación y tratamiento del paisaje agrícola mediante el uso continuado de técnicas tradicionales ${ }^{35}$ :

- Rotación de cultivos (rotazione): la secuencia en el tiempo de cultivos complementarios en el mismo campo para favorecer el equilibrio de los nutrientes en el suelo. Convierte el agroecosistema en complejo, acercándose al ecosistema natural con capacidad de autorregulación (Ver Mapa 4).

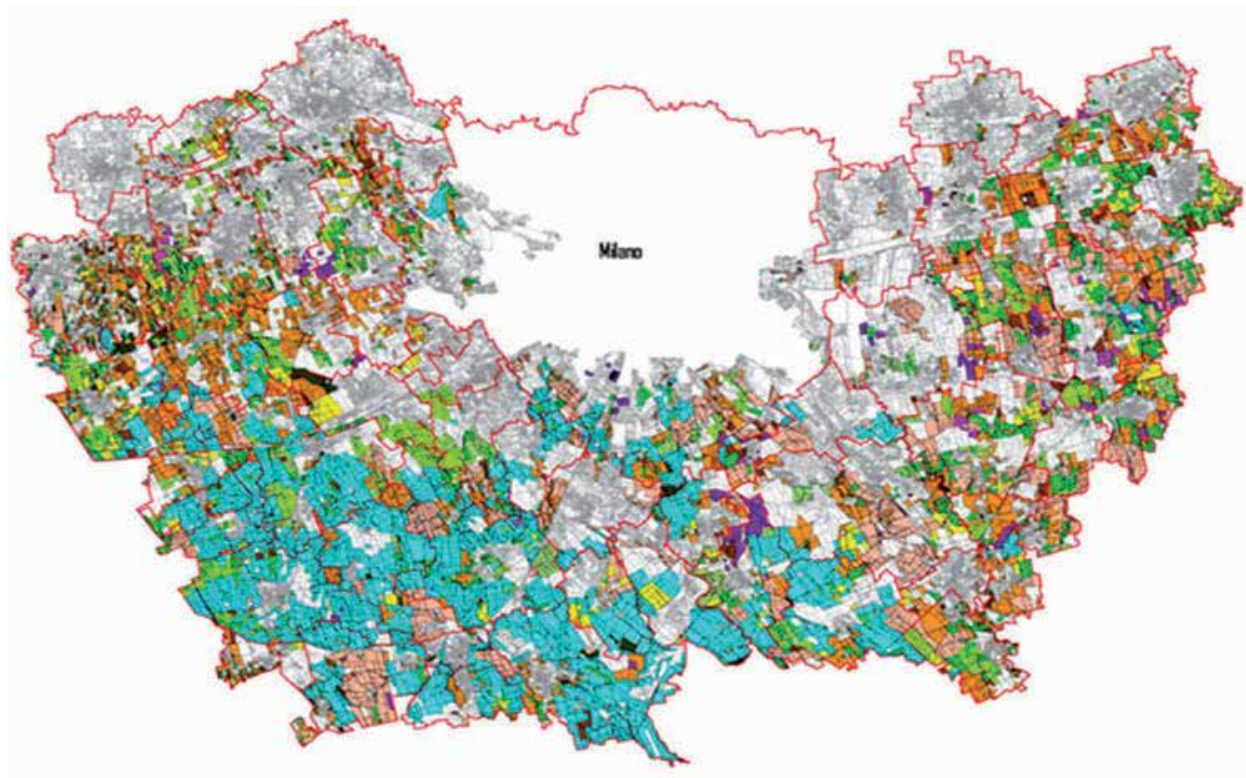

- La asociación de cultivos (consoziacione): la presencia simultánea de dos o más especies cultivadas en un mismo campo (una pradera natural o un bosque son ejemplos de ello).

- Los terrenos de inundación (marcite): la cubrición de los campos con un velo de agua que fluye proveniente de manantiales, protegiendo los campos en invierno. Permite una productividad excepcional de la tierra, le permite tener hasta ocho siegas de forraje al año.

- El uso de agua de manantiales y acequias capilares que conectan los canales (elaborados por la comunidad cisterciense durante el Medioevo). ${ }^{36}$

En síntesis, el territorio agrícola se ordena y protege como un invaluable patrimonio que juega un papel decisivo en estructuración del paisaje rural como productor de bienes y beneficios para la comunidad. Además, los cultivos fomentan un "ambiente" propicio para que la

33 Ibídem

34 Ibídem

35 Provincia di Milano, Plan del Sector Agrícola, disponible en Internet en: http://www.provincia.milano.it/parcosud/, Milano, 2007

36 Ibídem
Mapa 4. Cultivos rotatorios en el PASM (resaltan las plantaciones de cereales y arroz, indicadas en azul)

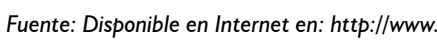
provincia.milano.it/parcosud/ 
Fotografía 3 Antigua cantera de arena y grava, ubicada en la localidad de San Martino Olearo

Fuente: La antigua cantera de arena y grava ubicada en la localidad de San Martino Olearo, dio paso a un lago artificial como parte del programa de recualificación paisajística de la zona. Fotografía del autor

agricultura pueda asumir nuevas funciones productivas y sociales a través de una estrategia urbana, territorial y ambiental sagaz e intuitiva para el futuro del área metropolitana milanés, en un intento por oponerse a la progresiva "pérdida de identidad de las zonas periféricas a través de una propuesta que valoriza la función agrícola y la hace compatible con la protección del medio ambiente y del paisaje". ${ }^{37}$

En consecuencia, el PTC del parque también propende por la salvaguarda de los resguardos ambientales, paisajísticos y naturales, contemplada en el Título III sección II del PCT y hace referencia a reservas naturales, zonas de interés naturalístico, zonas de transición entre las áreas agrícolas y las de interés naturalístico, zonas de protección en ámbitos fluviales y las zonas de tutela y valorización paisajística. ${ }^{38}$ Este escenario no yace en ningún momento estático o imperturbable pues el PTC vela por crear ámbitos de fruición en beneficio de la población y de la productividad y sostenibilidad del PASM. Así bien, el PTC ordena y tutela en sus contenidos las zonas equipadas para la fruición recreativa, educativa, deportiva y social subordinándolas a las exigencias de tutela del ambiente y de la salvaguardia del ambiente. Resaltan en esta sección del PTC los lineamientos para reequilibrar los flujos de usuarios hacia preexistencias como parques urbanos e instalaciones deportivas y recreativas, se planifica la apertura de otras para evitar fenómenos de concentración que puedan afectar la actividad agrícola. ${ }^{39}$ En consecuencia, se da preferencia a las actividades que comporten la fruición de la naturaleza y la utilización de espacios abiertos de manera tal de "extender el uso público y promover la máxima utilización del patrimonio del parque por parte de todos los ciudadanos en respeto de los valores del ambiente agrícola y natural". ${ }^{40}$ Esto significa que se promueven obras de recuperación de edificios rurales existentes sólo para fines agro turísticos o actividades relacionadas con la arquitectura permitiéndose la aparición de nuevos parqueaderos estrictamente ligados a dichas actividades, se incentiva la creación de senderos peatonales, ciclísticos y ecuestres y se restringe la construcción de nuevos hechos arquitectónicos con excepción de tipologías higiénico-sanitarias. Otro aspecto interesante es la recuperación de antiguas minas y excavaciones, hoy en día inactivas en el Parque, con fines destinados a la recualificación del paisaje y al impulso de actividades de esparcimiento (Ver Foto 3).

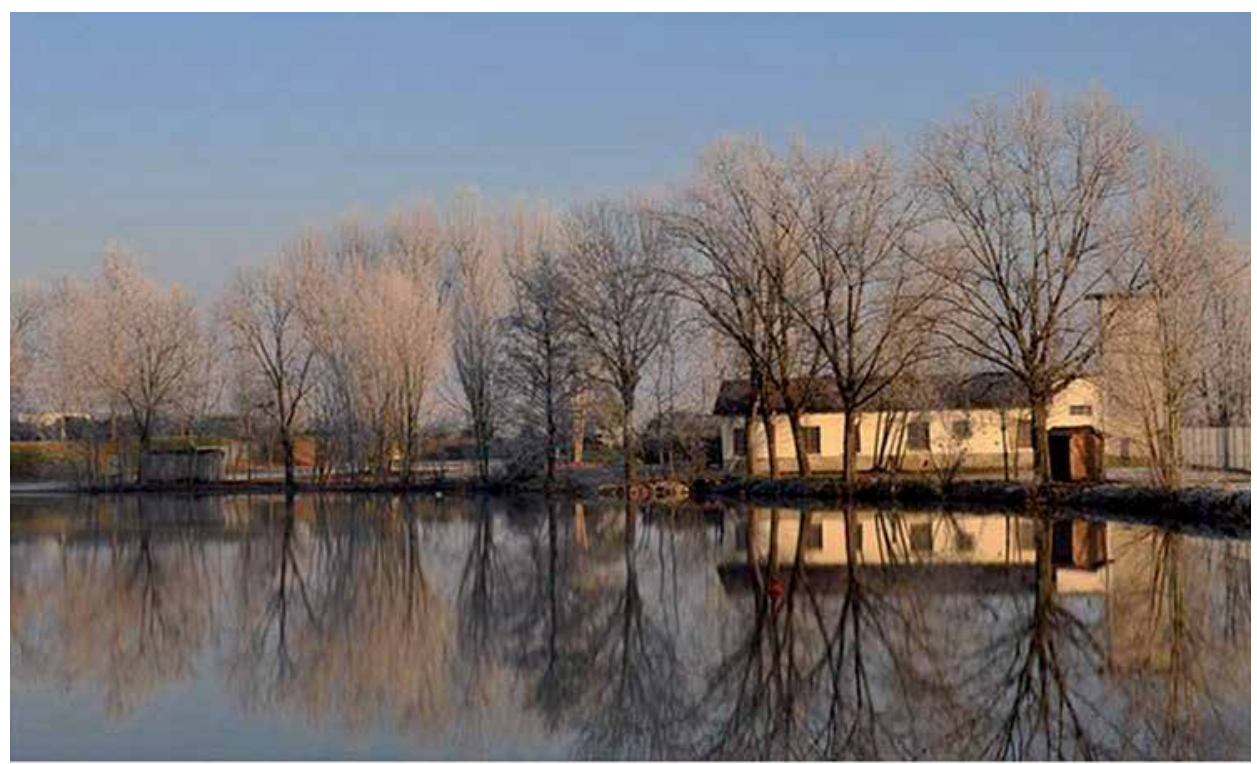

37 ERBA, V. Op. Cit., p. 81

38 Región Lombardía, Plan Territorial de Coordinación del Parque Regional Agrícola Sur Milán, Op. Cit.

39 Normas generales y ámbitos de la fruición (Título III, Sección III, Art. 35 al 37) Región Lombardía, Plan Territorial de Coordinación del Parque Regional Agrícola Sur Milán, Op. Cit.

40 Región Lombardía, Plan Territorial de Coordinación del Parque Regional Agrícola Sur Milán, Op. Cit. 
Los anteriores ámbitos están directamente ligados a los elementos puntuales de tutela ambiental, paisajística, arquitectónica y monumental que constituyen uno de los componentes que aumentan notablemente el valor del patrimonio presente en el territorio del PASM. Seguramente, uno de los apartes más interesantes del PTC ya que es aquí donde se tutelan los núcleos y asentamientos rurales de interés paisajístico y de gran valor histórico y monumental, los edificios en "emergencia histórico-arquitectónica", obras relativas a la "historia agrícola" del territorio, rutas de interés histórico-paisajístico y el los recursos hídricos del Parque. ${ }^{41}$ Se trata, de hecho, de todo el patrimonio histórico del territorio, inventariado desde épocas pasadas en documentos que registran la evolución histórica del territorio del PASM y que muestran cómo el hombre actuó como "planificador empírico", trabajando inicialmente en importantes obras hidráulicas encaminadas a una correcta utilización de los recursos hídricos allí presentes y que dieron origen a una gran estrategia de canalización en los campos así como a las praderas de inundación (en italiano marcite), el uso de las aguas subterráneas, la construcción de canales navegables obras que hicieron de esta área un espacio único en términos de agricultura (ver foto 4$){ }^{42}$

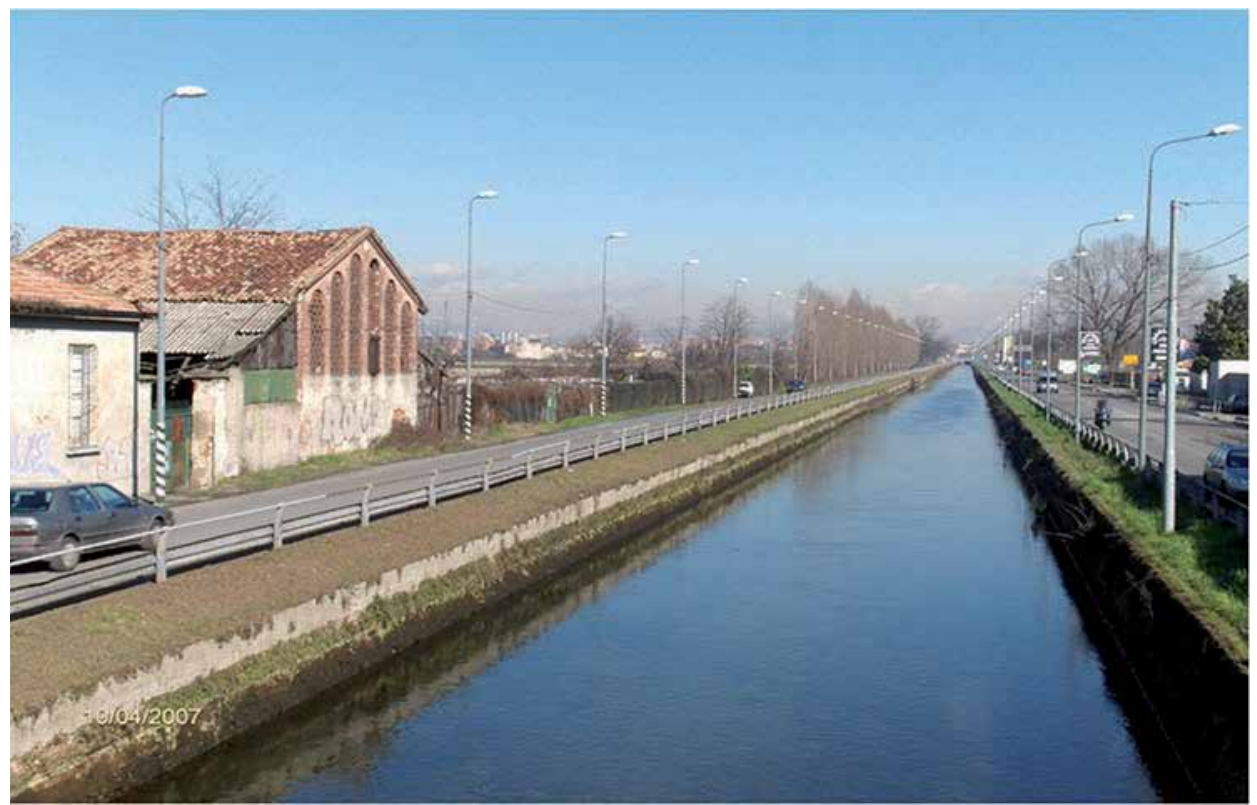

Es así que durante siglos, el territorio observa un desarrollo alrededor de este recurso primario, iniciado con la aparición de las abadías (ver Foto 5$)^{43}$, luego los castillos y posteriormente núcleos y asentamientos rurales donde se edificaron palacetes, molinos, granjas y edificaciones típicas de la zona (cascine) ${ }^{44}$. Estas últimas se encuentran dispersas en todo el territorio ocupado por 1400 explotaciones agrícolas que emplean a más de 4.000 trabajadores (Ver Foto 6). ${ }^{45}$
4I Título III sección IV Art. 38 al 44, Región Lombardía, Plan Territorial de Coordinación del Parque Regional Agrícola Sur Milán, Op. Cit.

42 Con "marcite" se define, en italiano, los prados sobre los cuales corre el agua durante todo el año. En español se podría traducir como "praderas de inundación: una técnica tradicional del norte de Italia que permite el crecimiento exuberante de hierbas de forraje. tradizionali. CHIAPPA, Mauri Luisa; FANTONI, Giuliana (a cura di ), Op. cit.

43 CHIAPPA, Mauri L.; FANTONI, G. (a cura di). Libro de li Prati del Monastero di Chiaravalle, - Provincia di Milano, Parco Agricolo Sud Milano, Archivio di Stato, Milano 200I. Esta obra es un estudio minucioso que se refiere a la cuidadosa recuperación de un documento, redactado el siglo XVI, con la finalidad de describir las posesiones de la Abadía cisterciense en el territorio hoy tutelado del Parque. Después de muchos siglos, esta obra ofrece una valiosa información, de carácter puntual, para comprender y proteger un paisaje de relevancia histórica y cultual.

44 La "cascina es una típica casa de campo del valle del norte de Italia, específicamente de Lombardía, Piamonte y parte de Emilia. Se trata de una enorme granja en medio de una finca o exploración agrícola de numerosas hectáreas, por lo general de 40 a 50 (en la Baja Llanura de regadío tienen un tamaño promedio de 40 a 100 hectáreas). AGOSTINI, Stella. Classificazione delle cascine del Parco Agricolo Sud, Milano, Franco Angeli/Urbanistica, 2000

45 BELTRAME, Gianni. II Parco Agricolo Sud Milano, Parco Agricolo Sud Milano, Arienti \& Maccarini, Milano
Fotografía 4. Canales de Milán

Fuente: (Navigli) son un sistema de canales de riego y de navegación, con baricentro en Milán. Con el suministro regular de agua proveniente de los canales se regaron y se hicieron productivas enormes áreas de este territorio, hecho estrechamente relacionado al trabajo de recuperación iniciado por los monjes de las abadías en el sur de la ciudad, yo presentes en el siglo décimo. La construcción de sistema duró desde el siglo XII hasta el siglo XIX. Fotografía del autor 
Fotografía 5. La Abadía de Chiaravalle

Fuente: es un monasterio cisterciense del siglo XII, ubicado al sur Milán y hace parte del patrimonio arquitectónico presente en e territorio agrícola del PASM, cerca de los distritos Vigentino y Rogoredo. En los alrededores de la abadía se desarrolló un burgo, una vez municipio independiente con el nombre de Chiaravalle, pero ahora hace parte del municipio de Milán y sede, entre otras cosas, de uno de sus cementerios

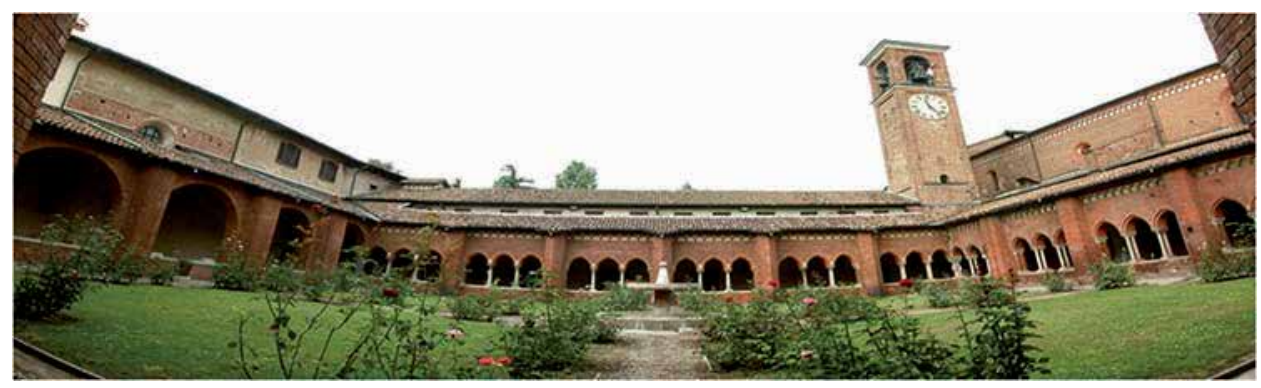

Fotografía 6. La cascina Gaggioli

Fuente: La Cascina Gaggioli comienza a aparecer bajo este nombre en los mapas de 1650 y es un fiel exponente de estas construcciones que se encuentran dispersas en el campo, a pocos kilómetros de los centros de población y distantes las unas con las otras. En su interior hay establos, heniles, silos, graneros, lecherías, pozos, fuentes, hornos, almacenes, molinos y viviendas campesinas, todo reunido en una sola estructura. La planta de esta estructura es cuadrada. En su centro se encuentra un gran patio alrededor de los cuales se dispones los diferentes edificios agrícolas. El patio tiene la vez la función de claustro. En las fincas más grandes se pueden encontrar dos o tres patios en cuyo caso se les llama de "patio múltiple". En algunos casos, las fincas más grandes también tienen un molino, una hostería, una capilla y a veces hasta una escuela. Mientras más aislada esté la "cascina" más tiende a tener la apariencia de una "fortaleza", dada la presencia de grandes muros perimetrales. También ha habido "cascine" fortificadas con fosos, puentes levadizos y torres. La imagen pertenece a Archivo fotográfico del la Cascina Gaggioli. Vía Selvanesco, 25 Milano

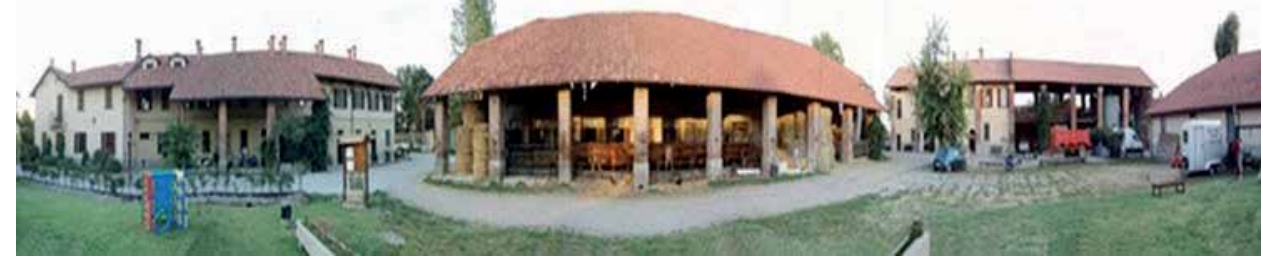

Por tal motivo la administración pública y le empresa privada trabajan mancomunadamente en una continua recuperación de todos estos bienes arquitectónicos y monumentales, dándoles un uso conforme al original, estrategia que ha demostrado ser una gran oportunidad para el Parque. ${ }^{46}$ En sustancia, se trata de un desarrollo del turismo rural simple y compatible con el medio ambiente (educación agroambiental, venta directa de productos locales, comer en las antiguas hosterías fuera de la ciudad, senderos didácticos en el paisaje rural tradicional) como una vía importante para la revitalización y promoción del patrimonio arquitectónico rural. ${ }^{47}$ Estas estructuras de gran valor histórico y arquitectónico junto a una serie de elementos naturales que caracterizan el Parque como manantiales, "oasis naturales", humedales, ríos, praderas y bosques dan como resultado final es un rico patrimonio cultural protegido por las Normas Generales de Tutela del PTC. ${ }^{48}$ Sin duda un instrumento contra el deterioro de la calidad ambiental del territorio Parque, característico de los años 60, debido a una edilicia discordante y desordenada, a la contaminación del agua y a la degradación generalizada de grandes superficies en las áreas periféricas de Milán y otros municipios. Hoy, la Provincia de Milán resalta la importancia de la gestión de este patrimonio dentro de criterios de compatibilidad con la vocación agrícola del Parque, tarea que parecía imposible debido a la ausencia de un instrumento unitario como el mismo Parque. ${ }^{49}$ En conclusión, un rico patrimonio ambiental, cultural y estético, en ámbito periurbano, protegido por un mecanismo estructural que responde a la necesidad de construir una alternativa de competitividad para aprovechar el creciente interés que la población muestra por el beneficio y la preservación de éste donde las funciones residenciales, de ocio y las de producción, traducen en gran medida una necesidad común por la reconstrucción del vínculo social con el territorio rural. ${ }^{50}$

46 Existen muchos ejemplos de la recuperación de los cortijos y de otras estructuras relacionadas con la tradición agrícola en el territorio del PASM. Por ejemplo, la Giazzera (congelador) de Cornaredo y los museos agrícolas de Albairate, Assago, Buccinasco, Milán y Rozzano transformados en centros de exposición y actividades culturales. Estos son apenas dos simples ejemplos que permiten entender cómo las estructuras de origen campesino, ligadas a la arquitectura rural (supuestamente denominada "menor") representan un importante recurso para la utilización cultural, educativa y recreativa en un parque agrícola. Ibídem

47 AGOSTINI, S. Classificazione delle cascine del Parco Agricolo Sud Milano, Franco Angeli/Urbanistica, 2000

48 Región Lombardía. Plan Territorial de Coordinación del Parque Regional Agrícola Sur de Milán, Op. Cit. y CITELLI, A.; GHIRINGHELLI, R. (a cura di), Parco Agricolo Sud Milano, Servizio Audiovisivi della Provincia di Milano, Milano, 1999

49 VIOLANTE, S. (a cura di),Provinciadi Milano, Parco Agricolo Sud Milano, Itinerari Storico Ambientali, Cooperativa Universitaria Editrice Scienze Politiche, Milano, 200I. La lectura de este volumen constituye una guía para descubrir las riquezas del PASM con itinerarios a través el patrimonio arquitectónico, paisajístico y ambiental.

50 FERRARESI, G. II Parco come Cura e Coltura del Territorio, un percorso di ricerca sull'ipotesi del Parco Agricolo, Milano, 2000 . 
La articulación de los territorios del parque se cierra con las áreas de tratamiento especial. EI PTC establece las normas y tratamientos para las áreas de explotación minera aún activas así como a las áreas con vínculo arqueológico y las abandonadas o con uso impropio. ${ }^{51}$ La Provincia de Milán cuida de la rehabilitación de sitios contaminantes mediante controles e inspecciones practicados durante la construcción y después de la terminación de los trabajos, en colaboración con la policía local. Estas tareas están asignadas a los delegados de la Región de Lombardía, asignados al PASM, quienes se ocupan de la planificación, emisión de autorizaciones y supervisión de las actividades mineras. El anterior recorrido por los principales contenidos del PTC permite concluir que la construcción de normas para el área del PASM parte del diagnóstico sobre las problemáticas que afectan el patrimonio existente $y$, por lo tanto, trae a flote la necesidad de un conocimiento profundo de la historia de los lugares, productos, métodos de producción, construcciones y tradiciones populares. ${ }^{52}$ Sin embargo, el conocimiento de la historia no es suficiente para salvar este patrimonio. Es necesaria una legislación ejecutada por los actores calificados para adelantar un oportuno gobierno del territorio apoyado en el principio de gobernabilidad, que apunta a optimizar los procesos de decisión que vigilarán y orientarán el presente y el futuro del PASM. ${ }^{53}$

\section{EL GOBIERNO DEL TERRITORIO: PROCESOS Y ACTORES PARA LA GESTIÓN DEL PATRIMONIO RURAL}

Actualmente, el PASM tiene su sede en las oficinas de la Provincia de Milán, ente Gestor del Parque y opera bajo las directrices establecidas en su reglamento, principal instrumento de gobierno del territorio "consagrado" al parque: contiene las normas constitutivas, objetivos, órganos y sus funciones, organización administrativa y las disposiciones legislativas del Parque. Este fue aprobado por el Consejo Directivo (nivel interno) en su reunión del 3 de julio de 1991 y por el Consejo Provincial (nivel Provincial) por resolución No. 20774/I I98/9 I de 23 de julio de 199I. Posteriormente, fue sancionado por la Junta Regional de Lombardía (nivel Regional) en sesión del 10 de diciembre de 1991. Entre los diversos poderes del Parque, como ente gestor, se destaca su potestad para proponer a la Región Lombardía modificaciones territoriales, según propuesta del Consejo Directivo. Los municipios pueden solicitar al Ente Gestor su adhesión y proponer su inclusión en los territorios del Parque según las finalidades del artículo No. 2 de la ley constitutiva. ${ }^{54}$ Sin embargo, el instrumento clave para la consecución de los objetivos de tutela y valorización es protección y la mejora es el ya citado Plan de Coordinación Territorial del Parque (PCT) que se erige como un instrumento innovador debido a la peculiar naturaleza del Parque Sud, la extensión y la articulación de su territorio, la importancia que en su seno reviste la agricultura y el aún controvertido "vínculo de inedificabilidad". Por último, pero no menos importante, encontramos los actores del PASM que se desempeñan dentro de una estructura administrativa, esencial para interpretar la política del parque, individuar la interacción entre los actores presentes, sus roles, las diferentes redes de conexión y definir nuevas normas y estrategias para la gestión de este territorio agrícola en "condición metropolitana".

5 I Reunidas bajo el título de "áreas" en el Título III Sección V del PTC, Título III sección IV Art. 38 al 44, Región Lombardía, Plan Territorial de Coordinación del Parque Regional Agrícola Sur Milán, Op. Cit. y http://www.provincia.milano.it/

52 Regolamento del Parco Agricolo Sud Milano, Provincia di Milano, Parco Agricolo Sud Milano, 2002

53 Para la elaboración de este articulo se consultaron el Reglamento del Parco Agrícola Sud Milano así como la ley de creación del Parque y las Normas técnicas para la aplicación del Plan Territorial de Coordinamiento aprobado con Decreto General Regional No. 7/818 del 3 agosto 2000.

54 Provincia di Milano, Parco Agricolo Sud Milano, Regolamento del Parco Agricolo Sud Milano, http://temi.provincia. milano. it/parcosud/regolamento.htm 
Figura 3. Los actores del "nuevo gobierno del territorio" del PASM

Fuente: elaborado por el autor

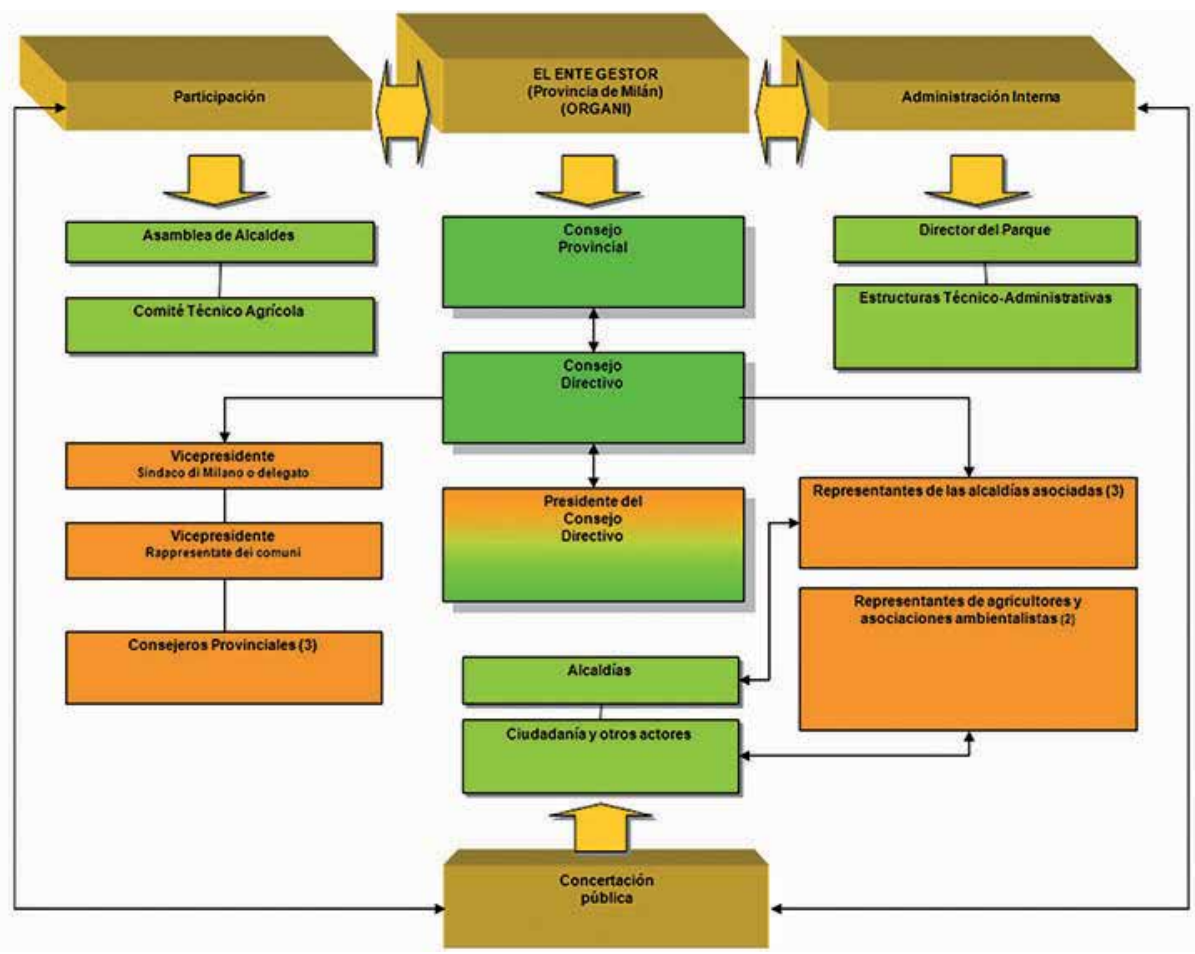

Este grupo de personas está compuesto por políticos y profesionales provenientes de diferentes disciplinas pero con un objetivo común, preservar el patrimonio rural y promover su conocimiento, conservación y cultura exclusiva en un ámbito de alta concertación ciudadana. En síntesis, los órganos del Ente Gestor se determinan en una escala de jerarquías y poderes, adjudicadas en primera instancia al Consejo Provincial y, el Consejo Directivo y el Presidente. ${ }^{55}$ Los detalles de los componentes administrativos del PASM se especifican en el reglamento del Parque, el cual explica a cabalidad la forma de articular el elemento humano, los mecanismos y la toma de decisiones de la entidad en cuestión (ver Figura 7). ${ }^{56}$ También hay que señalar que la gestión y planificación del territorio por parte del Parque, así como las actividades profesionales realizadas por técnicos externos, son apoyadas por el Sistema de Información Territorial del Parque Agrícola Sud Milano (SITPAS), que permite gestionar los datos existentes o recogidos durante el desarrollo del proyecto, relacionados con la agricultura y el medio ambiente. ${ }^{57}$

\section{LA GOBERNABILIDAD PARA UN PATRIMONIO TERRITORIAL SOSTENIBLE}

El PASM es un moderno diseño espacial para una nueva realidad desde el punto de vista de la gestión de recursos humanos y productivos, en una actual y variada relación entre hombre y naturaleza. Para ello es crucial también reflexionar sobre la gestión de espacios naturales, mediante el concepto de gobernabilidad, sugerido en gran medida por la Unión Europea. ${ }^{58}$ Por ende, una de las principales estrategias ha sido el proceso de concertación ciudadana que inicia con estrategias para divulgar a todos los niveles sociales el conocimiento del valor del patrimonio rural y de igual modo promover adecuadas metodologías

55 Provincia di Milano, Parco Agricolo Sud Milano, Regolamento del Parco Agricolo Sud Milano, Milano, 2002

56 Para obtener información adicional sobre las leyes del Parque Agrícola, los entes y otros mecanismos, se sugiere visitar el sitio Web del Parque Agrícola http://www.provincia.milano.it/parcosud/regolamento/organi.html o consultar el texto editado por la Provincia de Milán: Parco Agrícola Sud Milano, Reglamento del Parco Agrícola Sud Milano, Milano, 2002

57 Información disponible en: http://www.provincia.milano.it/parcosud/sitpas/index.html

58 BALDUCCI, Alessandro. Guida alla Governance del Parchi della Provincia di Milano. CALVARESI, Claudio; GFELLER Caterina; LONGO, Antonio (a cura di), pp. 3-4 
para la conservación y la fruición de los bienes en cuestión. ${ }^{59}$ Esto significa que dentro del perímetro del Parque se ofrece una variedad de servicios diseñados para llevar el proyecto a convertirse, entre otras cosas, en un modelo de desarrollo social, económicamente sostenible. Se trata de una red, estructurada a partir de coyunturas privadas denominadas "Puntos Parque" que además de la promoción del proyecto del PASM, estructurada en términos de una amplia publicidad y visibilidad de datos e información, a través de la creación de sitios Web específicos y otras publicaciones, conforma un tejido adaptable y creciente donde se desarrollan actividades de información y distribución del material producido con el fin de promover las iniciativas del Parque. (Ver Fotografía 7).
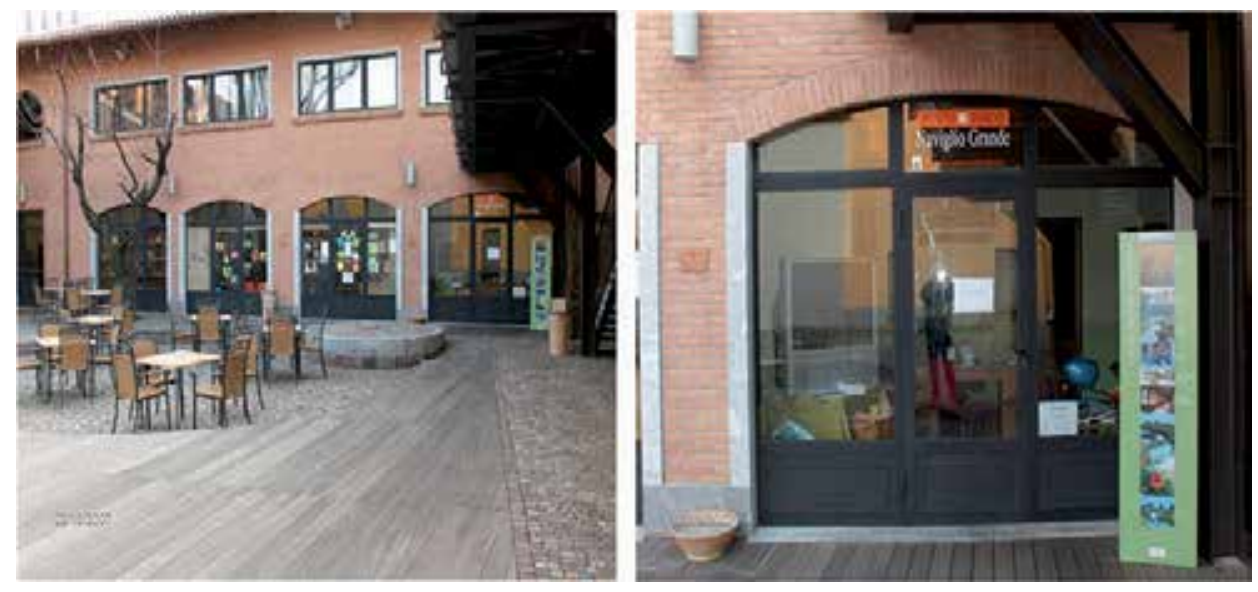

La idea es "llevar el parque a los ciudadanos", al establecer custodias en los lugares visibles y visitados con el propósito de abrir nuevos canales de comunicación y participación, más directo y adecuadamente difundido (Ver Mapa 5). En consecuencia, la orientación de las políticas públicas (incentivos y regulaciones), ha sido enmarcada dentro una estrategia de promoción social del territorio. ${ }^{60}$ Esto implica proponer acciones destinadas a consolidar la identidad del Parque con el objetivo de promover la interacción entre los actores, a través de un ambiente propicio para la formulación y la ratificación de los proyectos en los cuales la sociedad toma el control del territorio. Es así que el ente gestor promueve y apoya una serie de iniciativas dirigidas a la sociedad, conjugadas en tres tipos de itinerarios que en un modo u otro se cruzan entre sí gracias a la multipolaridad e interdisciplinariedad de las acciones llevadas a cabo allí: itinerarios didácticos, culturales y turísticos. ${ }^{61}$

Este proceso de concertación y participación pública también involucra el sector productivo de la población: agricultores, emprendedores, terratenientes y asociaciones públicas y privadas que exponen sus inquietudes y demandas a través de los concejales y representantes que tienen una curul en el Consejo Directivo del PASM (Ver Figura 3). Todo este proceso de interacción social gravita alrededor de una idea simple pero funcional que se basa solamente en la conexión de dos puntos:

- La conservación del patrimonio territorial, reconocido como una exigencia social cada día más tangible y constante.

- La valorización del patrimonio territorial como un instrumento que favorece la generación de recursos específicos que pueden ser movilizados para el desarrollo económico de las zonas rurales.

59 Strategie divalorizzazione del patrimonio rurale, AGOSTINI, S.; GARUFI, S. (a cura di). Franco Angeli/Urbanistica, 2000

60 EI PASM suministra una lista detallada de las explotaciones agrícolas (fincas y granjas, entre otras) presentes en el territorio y además promueve las actividades programadas por los administradores de las mismas. Para mayor información consúltese http://ambiente2.provincia.mi.it/agricoltura/Produzioni/agri_aziende.php

6I Para mayor información, se sugiere visitar la página Web del Parque http://www.provincia.milano.it/parcosud/ index.jsp
Fotografia 7. Punto Parque (Naviglio Grande) del PASM

Fuente: El carácter productivo del Parque coexiste con la utilización social del medio (servicios deportivos, recreativos, culturales, entre otros) En las fotos se aprecia la reutilización de una vieja estructura residencia en el municipio de Corsico que aloja uno de los Punto Parque (Naviglio Grande) del PASM. Fotografías del autor 
Mapa 5. Localización de los Puntos Parque sobre el territorio del PASM

Fuente: PASM - Oficina Proyectos Puntos Parco ${ }^{62}$

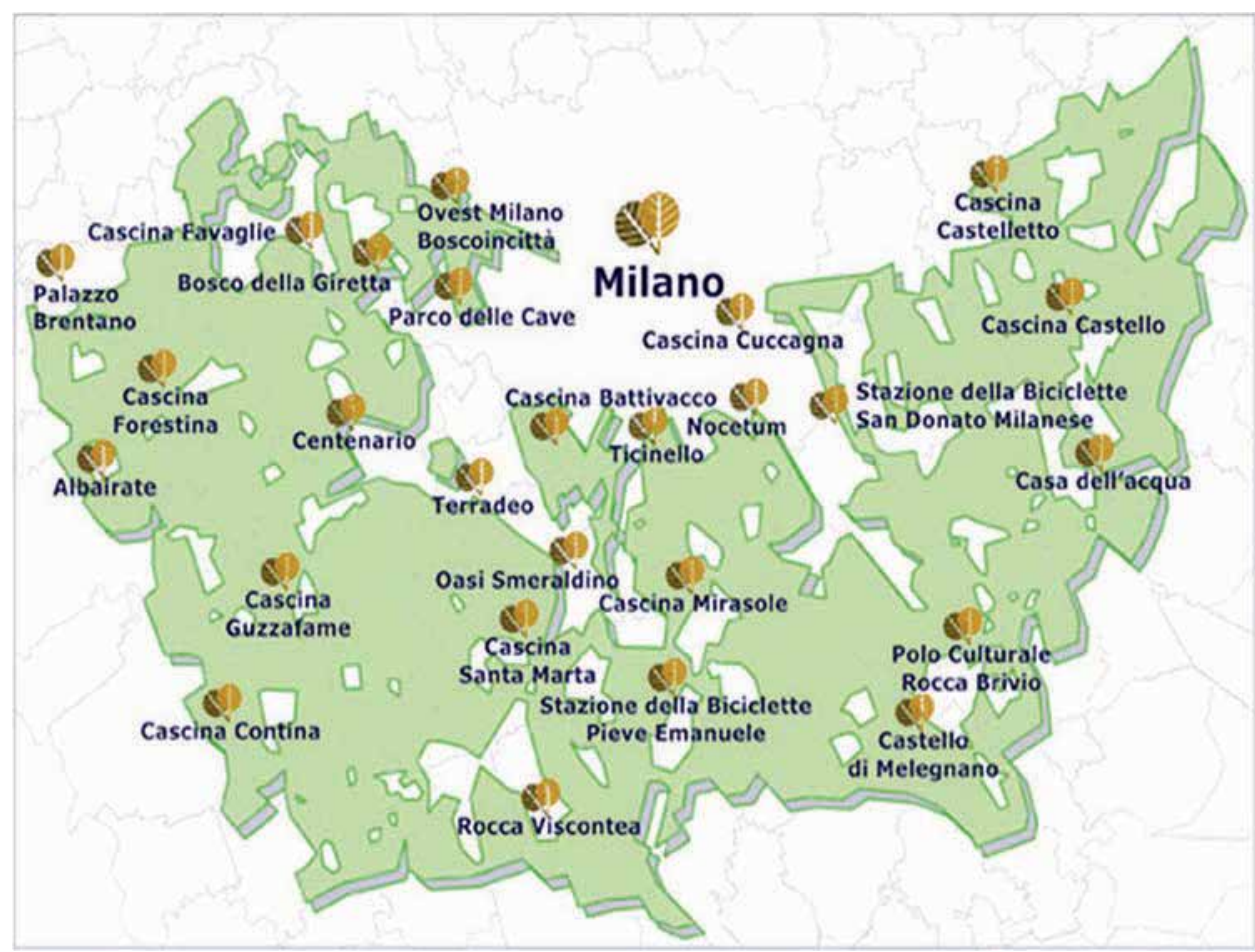

En conclusión, el PASM le apuesta a una perspectiva social que apunta a la diversificación de actividades como a la especificación de los efectos, ámbito que presupone, por lo tanto, la definición de normas específicas y su aplicación mediante una adecuada gobernabilidad centrada en la construcción de dispositivos de coordinación entre la administración pública y la ciudadanía.

\section{EL DESAFíO DE LA SOSTENIBILIDAD DEL PARQUE AGRÍCOLA SUR DE MILÁN}

Los problemas del PASM son ciertamente inherentes al contexto en el que está inscrito el proyecto: la vasta área del sur de Milán, cerca al denso desarrollo urbano de Milán, no es una excepción. El primer problema está relacionado con el tamaño del parque en sí y, por lo tanto, se verifican dificultades para dar cumplimiento de sus objetivos, relacionados con la tipología de Parque (por ejemplo, protección de la agricultura como función netamente económica y productiva). El proyecto, de hecho, abarca un gran número de municipios y en numerosas ocasiones el alcance de los objetivos no se percibe en todo el territorio. Un ejemplo sería el fracaso de la renovación en algunas zonas periféricas, probablemente a causa de un liderazgo eficaz, en ámbito municipal, de las transformaciones del territorio a las cuales el Parque se opone sólo con una restricción edificatoria, dinámica que conduce a delinear un territorio caracterizado por un mosaico de áreas libres, inactivas y no edificables. Esta situación llevaría a dictaminar a priori que el poder del PASM reside más en su vínculo de salvaguardia (Lr 24/90) que en su condición de verdadero instrumento de organización territorial. ${ }^{63}$ Aquí entra en juego otro dilema relacionado con el tipo de plan propuesto: el PASM se encuentra en un nivel superior al poder de las alcaldías municipales ya que éste, en su condición de

62 Parco Agricolo Sud Milano, Punti Parco - Programma 2007, Provincia di Milano, Milano, 2007. Gentil concesión del Dr. Eugenio Crenca (Responsable Proyecto Puntos Parque)

63 Es desde 1990 que con la reforma de las Autonomías Locales instaurada por la Ley 142, las Provincias asumieron funciones de Planificación local junto a las Regiones y a las Municipalidades. Para mayor información consúltese http://www.provincia. milano.it/pianificazione_territoriale/piano_territoriale/index.html 
ente jurídico y legislativo, legalmente constituido, emana opiniones sobre la actividad urbanística de los municipios y asimismo establece restricciones para la actividad edilicia sobre el territorio del Parque. Además, existen problemas relacionados con el grado de compatibilidad entre los diferentes niveles de protección que implica la existencia del Parque y las expectativas de crecimiento de los municipios que pertenecen a él. Se verifican entonces algunas dificultades de nivel político en términos de capacidad de diálogo entre la Provincia y algunas administraciones municipales que ven bloqueadas sus propias decisiones urbanísticas, contenidas dentro de los limites de cada casco urbano, precedentemente establecidos por concertación entre el PASM y cada alcaldía, restándole a éstas autonomía en la gestión de los recursos del territorio. Es este el problema más conocido entre los actores públicos: la restricción edificatoria (vínculo de in-edificabilidad), a veces clasificado como un instrumento aislado y no adecuado para gestionar los inevitables cambios en el paisaje de la periferia urbana o como un paliativo, ante la ausencia de un eficaz marco supra-municipal, no adecuado del todo para contrarrestar el avance de la urbanización y preservar el patrimonio arquitectónico. ${ }^{64}$

Entran en juego al mismo tiempo, las discrepancias de carácter técnico y productivo relacionadas con el ampliamente predominante uso agrícola, entre estas su "fragilidad dentro del sistema agroalimentario milanés" ya que la agricultura del parque tiene poca conexión con la cadena vertical de producción y transformación a causa de la falta de un clúster de empresas suficientemente estructurado. Como consecuencia, los productos del parque se mantienen a un precio superior al de los productos tradicionales (un 20-30\% más caro). Esto implica más inversión por parte de los emprendedores de las empresas agrícolas del parque, en aras de hacerlas más competitivas, con respecto a otras zonas, en términos de producción, sistemas de transformación y de comercialización de los productos para asegurar su supervivencia. ${ }^{65}$ Otra contradicción en el sistema productivo es que las empresas procesadoras asentadas en el parque tienen poco que ver con sus explotaciones productivas, pues más de la mitad de las materias primas que manufacturan las empresas del parque proceden del extranjero, especialmente en lo que respecta a productos como el trigo, esencial en la fabricación de pastas, alimento nacional. ${ }^{66}$ Por suerte el mercado ecológico se ha convertido en uno de los puntos fuertes de la provincia de Milán y se busca consolidar en el sistema milanés debido a la variedad en los puntos de venta. A simple vista sobresalen los mercados 'verdes' en casi todos los municipios, puntos de venta y distribución a supermercados que comercializan productos lácteos y hortofrutícolas así como restaurantes que utilizan productos que provienen de cultivos ecológicos. ${ }^{67}$

A esta serie de problemas productivos del sector primario se suman las formas de utilización del territorio agrícola por parte de los ciudadanos con fines recreativos, culturales y educativos. Este problema se registra en otros parques de la Provincia de Milán, porque no es fácil de combinar la agricultura intensiva con pesadas formas de “fruición". Además, existen fricciones entre agricultores y ecologistas por los métodos modernos de cultivo de alta rentabilidad y bajo empleo de mano de obra, que al final contaminan por la utilización de sustancias químicas, lo cual es objeto de preocupación pública. Finalmente, se denuncia también la preocupación por diferentes propuestas de implantación de infraestructuras, presentadas en los últimos años para el área metropolitana de Milán y, en particular, para el territorio del Parque el cual es el eslabón más

64 CALVARESI, Claudio; GFELLER, Caterina; LONGO, Antonio (a cura di), Op. Cit., p. 30

65 MORATALLA ZAZO, Ana. El Parque Agrícola del Sur de Milán: La primera incorporación de un espacio agrícola periurbano al sistema urbano, Op. Cit

66 lbídem

67 Información disponible en Internet en: www.provicia.mi.it/parcosud 
grande de los que debería ser en un futuro el gran cinturón verde de Milán. ${ }^{68}$ A esta preocupación se suma la implantación de la Exposición Universal de 20I5, que aunque se sitúe en terrenos externos al parque, prevé "proyectos oficiales prevalentemente concentrados en un recinto situado en una nueva expansión y con un alto consumo del suelo, que ponen en peligro una de las últimas zonas libres (originalmente agrícolas) en el zona noroccidental del área metropolitana de Milán". ${ }^{69}$ De cualquier manera, toda esta serie de problemas requiere un amplio debate sobre la relación de convivencia entre el Parque y las funciones, las instalaciones, las infraestructuras y las prácticas de uso de la ciudad contemporánea.

\section{HACIA LA VALORIZACIÓN DEL PATRIMONIO RURAL EN COLOMBIA}

El tema central de este análisis es sin duda la forma en que todos los elementos naturales y antrópicos presentes sobre el territorio del PASM han sido ordenados según un modelo particular, que proviene de algunas hipótesis entre las cuales resalta la producida por Giorgio Ferraresi: un parque que "coincide" con el territorio, rechaza la visión de parque como una estructura independiente, especializada y asume, por el contrario una cultura productiva que posteriormente destina una porción de tierra "al ocio" pero que de cualquier modo identifican en el parque el reflejo de una cultura o civilización urbana y rural. Además, la exploración de las áreas protegidas de la Provincia de Milán y en especial la del PASM, ayuda a identificar la concepción del parque como una estructura territorial vasta y compleja que asume un papel de contención de la expansión urbana, reequilibrio de los asentamientos, rehabilitación del medio ambiente y, además, productora de bienes gracias a la agricultura.

Estos caracteres hacen del parque un modelo bastante original ya que de un lado aparece la determinación para proteger y rehabilitar ámbitos agrícolas, paisajísticos y ambientales del territorio rural adyacente a la ciudad $y$, por el otro, la oportunidad de garantizar el equilibrio ecológico de la zona metropolitana con el objetivo de proteger la identidad de su territorio. De igual modo, sobresalen los mecanismos para el gobierno del territorio, dentro de los cuales resalta la controvertida restricción de edificabilidad que propende por preservar, fortalecer y actualizar a toda costa, la sostenibilidad de las zonas agrícolas al desalentar nuevos desarrollos dispersos, a través de propuestas dirigidas al aprovechamiento y recuperación de las zonas ya urbanizadas, en particular las áreas abandonadas. Además tienen importancia otras estrategias como la conservación de los elementos puntuales de valor arquitectónico y ambiental y el aumento del uso público mediante la valorización de la red de cortijos (cascine), estructuras ligadas fuertemente al agroturismo y que entran a hacer parte de las directivas destinadas al disfrute cultural y recreativo del ambiente por parte de los ciudadanos. A partir de este último principio se desprende además la idea de crear centros para la educación ambiental y el uso de los entornos naturales para dar visibilidad al proyecto. Se puede, entonces, concluir que todo el estudio del paradigma del Parco Agrícola del Sur de Milán recoge numerosas posibilidades de análisis, en función del contexto de estudio y corrobora además el concepto de que patrimonio rural no es homogéneo.

En consecuencia, este patrimonio demanda estudios ínter-disciplinares y precisa la participación de historiadores, agrónomos, arqueólogos, arquitectos, urbanistas,

68 El conjunto de estas consideraciones tienen como soporte las opiniones de diferentes ciudadanos, actores y observadores, expresadas en entrevistas, Internet, foros y varios ejercicios académicos de la Facultad de Arquitectura del Politécnico de Milán.

69 DI VITA, Stefano. Milano Expo 20I5. Un'occasione di sviluppo sostenibile. Milano, Franco Angeli, 2010 
antropólogos y geógrafos, entre otros, que aporten sus conocimientos específicos en pos de su protección y de su sostenibilidad. Sin duda, la creación del sistema de áreas protegidas en Italia abrió una "nueva temporada de cooperación" entre los sistemas productivos y la valorización del territorio rural dentro de una perspectiva que involucra el desarrollo sostenible y el equilibrio del medio ambiente.

Esta estrategia puede tomarse como la ruta correcta para llegar a la valorización del patrimonio rural en Colombia, la cual puede establecer inicialmente "conectividades" entre las exigencias socio-económicas actuales, la memoria colectiva y las riquezas naturales de cada región. Esto implica que cada municipio deberá promover una nueva representación de su patrimonio territorial para construir una conciencia ciudadana sobre sus propios valores hereditarios y el potencial de una "producción sostenible de riqueza", seguramente alcanzable a través de un puente cimentado en el fomento de proyectos, planes y políticas que puedan generar una nueva economía social, basada en la valorización del patrimonio mismo. Sólo de esta manera se puede hablar de un nuevo municipio que apoya y valora los actores económicos, sociales y culturales de las áreas rurales que participan creativamente en la formulación de proyectos que potencien el valor del patrimonio territorial. El ámbito rural adquiere, por ende, una nueva centralidad en este proceso de valorización del patrimonio: los nuevos agricultores no sólo producen bienes para el mercado sino también bienes y servicios públicos, subsidiados por el nuevo municipio para cuidado del medio ambiente, del paisaje y de la calidad urbana. Al asumir el proyecto del Parque Agrícola Sur de Milán como un reto para muchas regiones metropolitanas de Colombia, se debe iniciar propiciando una nueva y verdadera dimensión del asociacionismo municipal que va más allá de una aparente fusión, que vive solamente en la cartografía pero que no trasciende ni arroja resultados satisfactorios.

Por lo tanto, cualquier proyecto para salvaguardar y promover el patrimonio territorial debe enfrentarse a la perspectiva de la integración, desafío que exige un proceso gradual de planificación interno, en ámbito municipal, pero que ve la luz con una adecuada concertación entre los municipios circunvecinos para continuar con nuevas adhesiones en el área o región de influencia. En otros términos, crear un ámbito de interés intereses supramunicipal en el cual debería dársele valor fundamental a estrategias que aborden temáticas fundamentales como el mantenimiento y gestión de los fondos administrativos para la agricultura, la promoción de actividades recreativas, de ocio y complementarias para el mejoramiento de la calidad del medio ambiente urbano, receptor de los beneficios que puede dar una política de dotación ecológica, salvaguardia de las áreas verdes, control de los nuevos desarrollos y disminución del impacto de las infraestructuras para la movilidad en el paisaje rural.

En síntesis, valdría la pena considerar el PASM como un modelo en el proceso de reorganización de las funciones y de los servicios municipales tener siempre en cuenta los pro y los contra que se han registrado durante el proceso asociativo de los $6 \mathrm{I}$ municipios. El resultado de la cuidadosa evaluación de todos estos factores podría traducirse en nuevas propuestas para el asociacionismo de los municipios en Colombia con el fin de garantizar a la ciudadanía igualdad de oportunidades para la materialización de sus diferentes intereses en todos los procesos de regulación necesarios para lograr la diversificación y la competitividad de las zonas rurales, asociadas a los nuevos procesos socio-económicos que enfrenta Colombia. En este contexto, es fundamental el apoyo de los ciudadanos y de los emprendedores agrícolas como piezas fundamentales para crear nuevos canales de promoción y de crecimiento de las innumerables oportunidades que ofrece el patrimonio rural, todo esto en el marco de un diálogo abierto en ámbito político. 


\section{BIBLIOGRAFÍA}

ACEVES GONZÁLEZ, Francisco de Jesús. La territorialidad: punto nodal en la intersección espacio urbano-procesos en Comunicación y Sociedad, núm. 30, DESC, Universidad de Guadalajara, Guadalajara, 1997

Agenzia Regionale per la Protezione dell'Ambiente. ARPA LOMBARDIA, Aree Protette della Lombardia in Revista Segnali Ambientali, ARPA, Milano, 2002

AGOSTINI, Stella. Classificazione delle cascine del Parco Agricolo Sud, Milano, Franco Angeli/ Urbanistica, 2000

Alcaldía de Roma, Sistema Informativo territorial integrado, Parques Agrícolas - Objetivos, disponible en Internet en: http://www.h50 I.net/art72-prg-roma-parchi-agricoli.aspx

AGOSTINI, S.; GARUFI, S. (a cura di) Strategie di Valorizzazione del Patrimonio Rurale. Franco Angeli/Urbanística, Milano, 2000

ÁLVAREZ VILLAR, Alfonso. "Territorio" en Diccionario UNESCO de Ciencias Sociales, Vol. V. España, Planeta- Agostini, 1988

Áreas protegidas en Italia. Información disponible en Internet en: http://www.parchiaccessibili.it/

BALDUCCl, Alessandro. Politiche e progetti per la città contemporanea in Architettura e Politica, Convegno Nazionale, Politecnico di Milano, Milano, 2007

BELTRAME, Gianni. II Parco Agricolo Sud Milano, Arienti \& Maccarini, Milano, 2000

Bollettino Ufficiale della Regione Lombardia, $2^{\circ}$ Supplemento straordinario al N. 38, Approvazione del Piano Territoriale di Coordinamento del Parco Agricolo Sud Milano,Milano, 2000

BONNEFOY, Serge. Agricoltura e diritto di cittadinanza, in Urbanistica No. 128 settembre dicembre 2005, INU, Roma, 2006

BORRI, Dino; BARBANENTE, Angela. Reviewing Self-Sustainability, in Plurimondi. An International Forum for Research and Debate on Human Settlements, vol. 4, Bari, Dedalo, 2000.

BRANDUINI, Paola. Learee agricole nei parchi periurbani italiani: verso nuovi modelli,in Urbanistica No. 128 settembre - dicembre 2005, INU, Roma, 2006

BUZO SÁNCHEZ, Isaac. Apuntes de Geografía Humana. IES Exremadura, Montijo, 2009

CALVARESI, Claudio; GFELLER, Caterina; LONGO, Antonio (a cura di) DIAP Politecnico di Milano - Provincia di Milano, Guida alla Governance del Parchi della Provincia di Milano, Bianca \& Volta, Milano, 2005

CAPOZZI, B.; PERABONI, C.; TREU, M.C. I Nuovi Segni Del Territorio, Diabasis, Reggio Emilia, 2007 
CELLURALE, María Teresa. Locus e lus. Observaciones sobre espacio y sistema a la luz del derecho romano, Revista de Derecho Privado, Universidad Externado de Colombia, ISSN 0123-4366, No. 16, 2009

Centro di Studi per la Programmazione Intercomunale dell' Area Metropolitana información disponible en Internet en: http://www.pim.mi.it/index.html

Confederazione Italiana Agricoltori, información disponible en internet en: http://www.cia.it/cia/ CONTINI, Stéphane (a cura di). L'agriculture et le tourisme de proximité : l'exemple de Pérignysur-Yerres, fiche, Bergerie Nationale, 2006

Comune di Milano, Normas Técnicas de Aplicación del Plan Regulador General (PRG), aprobado el 26/2/1980, con las modificaciones aportadas al variante aprobado por la Junta Regional Lombarda el 5/7// 988 deliberación n. 35625, Milán, 1988

CHIAPPA, Mauri Luisa; FANTONI Giuliana (a cura di), Libro de li Prati del Monasterio di Chiaravalle, Provincia di Milano, Parco Agricolo Sud Milano, Archivio di Stato, Milano, 200 I

DELLA FRANCESCA, V.; D'ALESSANDRO, F. (a cura di), Orti: Racconti di vita tra gli ortaggi, Parco Nord Milano, Milano, 2004

DEMATTEIS, Giuseppe. Le metafore della terra. La geografia umana tra mito e scienza, Feltrinelli, Milano, 1985

ERBA, Valeria. Strumenti Urbanistici per Interventi di Qualità, Franco Angeli, Milano, 200 I

FEDENATUR (Fédération Européean des Espaces Naturels et Ruraux Métropolitains et Périurbains), The place of periurban natural spaces for a sustainable city,Fedenatur, Barcellona, 2004

FERRARESI, Giorgio; COVIELLO, Francesco. Vitalità del parco agricolo e reinterpretazioni in corso,in Urbanistica No. 128 settembre - dicembre 2005, INU, Roma, 2006

FERRARESI, Giorgio; MORETTI, A.; FACCHINETTI, M. (a cura di), Reti, Attori, Territorio. Forme e Politiche per progetti di infrastruttura, Franco Angeli, Milano,2004

FERRARESI, Giorgio; ROSSI, Anna. II Parco come Cura e Coltura del Territorio. Un Percorso di ricerca sull'ipotesi del Parco Agricolo, Grafo, Brescia, 1993

GAMBINO, Roberto. Per ricostruire il rapporto uomo-natura, Parchi, Vol. 32, The InterUniversity Department of Territorial Studies and Planning (DITER), Torino, 200 I

GOMARASCA, S. (a cura di), Indagine conoscitiva sui fontanili del Parco Agricolo Sud Milano, Provincia di Milano, Parco Agricolo Sud Milano, WWF, Milano, 2002

HERMOSILLA PLA, Jorge. Conocer el patrimonio rural: ¿Lujo o necesidad? En el Lebrillo Cultural. No, 2I, Venta del Moro, 2004

Instituto para la Tutela y Valorización de la Agricultura periurbana ISTVAP. Información disponible en Internet en: http://www.istvap.it 
Istituto Nazionale di Economia Agraria Información disponible en internet en: http://www.inea.it/

LEGUEN DE LACROIX, Eugène. L'agricoltura e l'ambiente. Fact Sheet Commissione Europea. Direzione Generale dell'Agricoltura, Bruxelles

MARCOU, Gérard. La cooperazione intercomunale nell'esperienza francese, Università di Parigi I e Gruppo di Ricerca sul Governo Locale in Europa (GRALE), Parigi, 2004

MAGNAGHI, Alberto. II Progetto Locale, Ballati Bonghieri, Torino, 2000

MORATALLA ZAZO, Ana. El Parque Agrícola del Sur de Milán: La primera incorporación de un espacio agrícola periurbano al sistema urbano El principio de una era de parques en el Espacio agrícola entre el campo y la ciudad, Universidad Politécnica de Madrid, Madrid, 2010

Parchi di Lombardia Información disponible en Internet en: Información disponible en internet en: http://www.parchi.regione.lombardia.it

Parchi Italiani Información disponible en Internet en: http://www.parks.it

PÉREZ RIVERA, William. Parco Agrario: Una manera de acercar la Universidad a la Región. Un Desarrollo Rural y Seguridad Alimentaria. Un reto para Colombia. Universidad Nacional de Colombia, Panamericana, Bogotá, 2004

PIRANI, Alberto; GAVIGLIO, Anna; LICITRA PEDOL, Martina. L'agricoltura in provincia di Milano 200I-2002, Tecnos, Milano, 2004

Provincia di Milano Información disponible en Internet en: http://www.provincia.milano.it

Provincia di Milano, Parco Agricolo Sud Milano, Regolamento del Parco Agricolo Sud Milano, Milano, 2002

Provincia di Milano, Plan del Sector Agricola, Información disponible en Internet en: http:// www.provincia.milano.it/parcosud/, Milano, 2007

Parco Agricolo Sud Milano, Punti Parco - Programma 2007, Provincia di Milano, Milano, 2007

Raffestein Claude, Per una geografia del potere, Unicopli, Milano, 198I

REBHOLTZ, Véronique; LENOBLE, Clément (a cura di). Charte de développement agricole de Vernouillet.

Redazione di Dove Rizzoli (a cura di), Parchi Lombardi-Cintura Verde Metropolitana, Rizzoli, Milano, 2003

Región Lombardía. Deliberación del Gabinete Regional del 3 de agosto de 2000. Aprobación del Plan Territorial de Coordinación del Parque Regional Agrícola Sur Milán (Art. I, 2, I.r. 86/83 y sucesivas modificaciones) en Boletín Oficial, 2 do. Suplemento extraordinario del número 38, Milán, 2000 
Ricerca Italiana Información disponible en Internet en: http://www.ricercaitaliana.it/

ROSIGNOLO, Cristina; SIMONETTA, Catterina (a cura di), Una Geografiadei Luoghi per lo Sviluppo Locale. Approcci Metodologici e Studi di Caso, Slot, Quaderno 3, Imarisio, 1989

SPISNI, Pierangela. Che cosa è la multifunzionalità? in L'Azienda Agricola Multifunzionale, Centro Studi Aziendali, Bologna, 2006

Santeramo, Paola. La cura della terra e le funzioni dell'agricoltura nelle aree periurbane per garantire l'accesso a prodotti di qualità e al bene paesaggio in Convegno Nazionale "Produzione agricola e nuovi paesaggi”. Istituto per la tutela e la valorizzazione dell'Agricoltura Periurbana, Milano, 2007

Treu, Maria Cristina (a cura di). II Sistema Rurale per la Progettazione tra Salvaguardia, Sostenibilità e Governo delle Trasformazioni.Convegno Internazionale, Libreria Clup, Regione Lombardia e Politecnico di Milano Cedat, Milano, 2004

United Nations World Turism Organisation Información disponible en Internet en: http://www. unwto.org

VIOLANTE, S. (a cura di). Itinerari Storico Ambientali,Provincia di Milano, Parco Agricolo Sud Milano, Cooperativa Universitaria Editrice Scienze Politiche, Milano, 200 I 